\title{
Effects of Annealing Environments on the Solution-Grown, Aligned Aluminium-Doped Zinc Oxide Nanorod-Array-Based Ultraviolet Photoconductive Sensor
}

\author{
Mohamad Hafiz Mamat, ${ }^{1}$ Mohd Izzudin Che Khalin, ${ }^{1}$ \\ Nik Noor Hafizah Nik Mohammad, ${ }^{2}$ Zuraida Khusaimi, ${ }^{2}$ \\ Nor Diyana Md Sin, ${ }^{1}$ Shafinaz Sobihana Shariffudin, ${ }^{1}$ \\ Musa Mohamed Zahidi, ${ }^{1}$ and Mohamad Rusop Mahmood ${ }^{1,2}$ \\ ${ }^{1}$ NANO-ElecTronic Centre (NET), Faculty of Electrical Engineering, Universiti Teknologi MARA (UiTM), \\ 40450 Shah Alam, Selangor, Malaysia \\ ${ }^{2}$ NANO-SciTech Centre (NST), Institute of Science (IOS), Universiti Teknologi MARA (UiTM), 40450 Shah Alam, Selangor, Malaysia
}

Correspondence should be addressed to Mohamad Hafiz Mamat, hafiz_030@yahoo.com

Received 8 June 2012; Revised 24 August 2012; Accepted 29 August 2012

Academic Editor: Raymond L. D. Whitby

Copyright ( 2012 Mohamad Hafiz Mamat et al. This is an open access article distributed under the Creative Commons Attribution License, which permits unrestricted use, distribution, and reproduction in any medium, provided the original work is properly cited.

\begin{abstract}
We have fabricated metal-semiconductor-metal- (MSM-) type ultraviolet (UV) photoconductive sensors using aluminium- (Al-) doped zinc oxide $(\mathrm{ZnO})$ nanorod arrays that were annealed in different environments: air, oxygen, or a vacuum. The Al-doped $\mathrm{ZnO}$ nanorods had an average diameter of $60 \mathrm{~nm}$ with a thickness of approximately $600 \mathrm{~nm}$ that included the seed layer (with thickness $\sim 200 \mathrm{~nm}$ ). Our results show that the vacuum-annealed nanorod-array-based UV photoconductive sensor has the highest photocurrent value of $2.43 \times 10^{-4} \mathrm{~A}$. The high photocurrent is due to the high concentration of zinc $(\mathrm{Zn})$ interstitials in the vacuum-annealed nanorod arrays. In contrast, the oxygen-annealing process applied to the Al-doped $\mathrm{ZnO}$ nanorod arrays produced highly sensitive UV photoconductive sensors, in which the sensitivity reached 55.6, due to the surface properties of the oxygen-annealed nanorods, which have a higher affinity for oxygen adsorption than the other samples and were thereby capable of reducing the sensor's dark current. In addition, the sensor fabricated using the oxygen-annealed nanorod arrays had the lowest rise and decay time constants. Our result shows that the annealing environment greatly affects the surface condition and properties of the Al-doped $\mathrm{ZnO}$ nanorod arrays, which influences the performance of the UV photoconductive sensors.
\end{abstract}

\section{Introduction}

Recently, zinc oxide $(\mathrm{ZnO})$ nanostructures have been widely studied because of their potential for various applications, including solar cells [1-3], light emitting devices [4], electron emitters [5, 6], photocatalysts [7], and sensors [8, 9]. The performance of devices containing one-dimensional (1D) $\mathrm{ZnO}$ nanostructures, such as nanobelts and nanorod arrays, has significantly improved because of the unique properties of these nanostructures, such as high mobility and a high surface-to-volume ratio $[10,11]$. $\mathrm{ZnO}$ nanorod arrays are very promising materials for use as sensing elements in ultraviolet (UV) photoconductive sensor applications because these arrays exhibit a fast response and high photocurrent and are highly sensitive to UV light $[10,12]$. The use of $\mathrm{ZnO}$ nanorod arrays in UV photoconductive sensors is attractive for practical applications because of the diversity of fabrication methods for these nanorods, their large surface availability, and excellent physical and chemical properties. In addition, the high surface-to-volume ratio of $\mathrm{ZnO}$ nanorod arrays produces better sensitivity to UV light compared to conventional $\mathrm{ZnO}$ thin films because the photoconductivity mechanism in $\mathrm{ZnO}$ is strongly related to the surface reaction activities [13]. ZnO nanorod arrays can be successfully grown on substrates using various methods, such as chemical vapour deposition (CVD) [14], metalorganic chemical vapour deposition (MOCVD) [15], pulsed laser deposition (PLD) [16], and solution-based techniques 
[17-20]. However, solution-based techniques offer many advantages over other synthesis methods capable of growing $\mathrm{ZnO}$ nanorod arrays at low temperature with low cost.

Generally, fabricated $\mathrm{ZnO}$ nanorod arrays, especially those prepared using solution-based techniques, contain a considerable number of defects, resulting in a low response to UV light. Because the UV photoconductivity is governed by the surface conditions of the nanorod arrays, effective fabrication methods should be developed to reduce the number of defects and improve the surface quality of the prepared $\mathrm{ZnO}$ nanorod arrays. A few approaches have been proposed that can enhance the performance of the ZnO-based UV photoconductive sensor by improving the $\mathrm{ZnO}$ surface condition and reducing the defects. These approaches include the use of polymer and metal surface coatings [13, 21-23] and plasma and chemical surface treatments [24-28]. These techniques facilitate efficient photogeneration processes in the $\mathrm{ZnO}$ under UV illumination, thereby contributing to improved performance of the device, such as a high and stable photocurrent, high sensitivity, and a fast photoresponse. However, annealing is also a $\mathrm{ZnO}$ surface treatment process that could remove surface defects and contamination, thereby improving the surface condition of $\mathrm{ZnO}$ [29-31]. Although the annealing temperature is widely reported to influence the performance of the UV photoconductive sensor [32-35], the effects of annealing under different environments have rarely been reported in terms of the performance of $\mathrm{ZnO}$ nanorodarray-based UV photoconductive sensors.

Herein, we reported on the performance of a UV photoconductive sensor developed using thin Al-doped $\mathrm{ZnO}$ nanorod arrays prepared using the sonicated sol-gel immersion method and annealed in different environments. The nanorod arrays were prepared in a very short immersion time, within $50 \mathrm{~min}$, using sonicated sol-gel immersion method, which yield small and thin nanorod arrays with an average diameter of $60 \mathrm{~nm}$ and thickness of approximately $600 \mathrm{~nm}$. We observed that annealing under different environments significantly influenced the surface conditions of the nanorod arrays, thereby affecting the performance of the UV photoconductive sensor.

\section{Experimental Procedure}

$\mathrm{Al}$-doped $\mathrm{ZnO}$ nanorod arrays were grown on a glass substrate that was coated with an $\mathrm{Al}$-doped $\mathrm{ZnO}$ seed layer using sonicated sol-gel immersion. The Al-doped $\mathrm{ZnO}$ thin film, which was used as a seeded catalyst, was prepared on the glass substrate using sol-gel spin-coating [36]. The solution for the seed layer was prepared using $0.4 \mathrm{M}$ zinc acetate dihydrate $\left(\mathrm{Zn}\left(\mathrm{CH}_{3} \mathrm{COO}\right)_{2} \cdot 2 \mathrm{H}_{2} \mathrm{O}, 99.5 \%\right.$ purity, Merck $)$ as a precursor, $0.4 \mathrm{M}$ monoethanolamine (MEA, $\mathrm{H}_{2} \mathrm{NCH}_{2} \mathrm{CH}_{2} \mathrm{OH}, 99.5 \%$ purity, Aldrich) as a stabiliser, $0.004 \mathrm{M}$ aluminium nitrate nonahydrate $\left(\mathrm{Al}\left(\mathrm{NO}_{3}\right)_{3} \cdot 9 \mathrm{H}_{2} \mathrm{O}, 98 \%\right.$ purity, Analar) as a doping source (to achieve approximately 1 at.\% Al-doped $\mathrm{ZnO}$ ), and 2-methoxyethanol as a solvent. The solution was then heated at $80^{\circ} \mathrm{C}$ and stirred using a hot plate magnetic stirrer for $3 \mathrm{~h}$ to yield a clear, homogeneous solution. The solution was further stirred at room temperature for $24 \mathrm{~h}$ for the ageing process. The seed layer was deposited onto glass substrate using spin-coating technique. The prepared solution was dropped onto glass substrates while the substrates were spun at 3,000 rpm for $60 \mathrm{~s}$. After the spin-coating process, the substrates were heated at $150^{\circ} \mathrm{C}$ for $10 \mathrm{~min}$ to evaporate the solvent and remove the organic component from the film. The coating was repeated five times to increase the film thickness to approximately $200 \mathrm{~nm}$. The prepared films then were annealed in air using a furnace at $500^{\circ} \mathrm{C}$ for $1 \mathrm{~h}$.

The solution for preparing the aligned $\mathrm{Al}$-doped $\mathrm{ZnO}$ nanorod arrays contained $0.1 \mathrm{M}$ zinc nitrate hexahydrate $\left(\mathrm{Zn}\left(\mathrm{NO}_{3}\right)_{2} \cdot 6 \mathrm{H}_{2} \mathrm{O}, 98 \%\right.$, Systerm) as a precursor, $0.1 \mathrm{M}$ hexamethylenetetramine (HMT, $\mathrm{C}_{6} \mathrm{H}_{12} \mathrm{~N}_{4}, 99 \%$, Aldrich) as a stabiliser, and $0.001 \mathrm{M}$ aluminium nitrate nonahydrate $\left(\mathrm{Al}\left(\mathrm{NO}_{3}\right)_{3} \cdot 9 \mathrm{H}_{2} \mathrm{O}, 98 \%\right.$, Analar) as a dopant, which were dissolved in deionised (DI) water. The solution was then sonicated at $50^{\circ} \mathrm{C}$ for $30 \mathrm{~min}$ using an ultrasonic water bath (Hwashin Technology Powersonic 405, $40 \mathrm{kHz}$ ) before being aged and stirred for $3 \mathrm{~h}$ at room temperature.

To deposit the aligned Al-doped $\mathrm{ZnO}$ nanorods, approximately $100 \mathrm{~mL}$ of the prepared solution was poured into a vessel that contained the horizontal glass substrates that were coated with the seeded catalyst at the bottom. The sealed vessel was immersed into a water bath deposition system at $95^{\circ} \mathrm{C}$ for $50 \mathrm{~min}$. After the deposition process, the samples were removed from the vessel and cleaned with DI water. The resulting $\mathrm{Al}$-doped $\mathrm{ZnO}$ nanorod arrays were heated at $150^{\circ} \mathrm{C}$ for $10 \mathrm{~min}$ to evaporate the water. Next, the samples were annealed at $500^{\circ} \mathrm{C}$ in an oxygen, air, or vacuum environment for $1 \mathrm{~h}$ using a furnace. Undoped $\mathrm{ZnO}$ nanorod arrays were also prepared using the same procedure and were annealed in air at $500^{\circ} \mathrm{C}$ for $1 \mathrm{~h}$. In addition, the $\mathrm{Al}$-doped $\mathrm{ZnO}$ nanorod arrays were prepared at different lengths of immersion time (i.e., 50, 100, and $150 \mathrm{~min}$ ) and were annealed in air at $500^{\circ} \mathrm{C}$ for $1 \mathrm{~h}$. To complete the metalsemiconductor-metal- (MSM-) type sensor structure, $60 \mathrm{~nm}$ thick Al-metal contacts were deposited onto the prepared nanorod arrays using a thermal evaporator at a deposition pressure of $4 \times 10^{-4} \mathrm{~Pa}$. The distance between the two metal contacts was $2 \mathrm{~mm}$.

The prepared nanorod arrays were characterised using field-emission scanning electron microscopy (FESEM, JEOL JSM-7600F), which was used to observe their surface morphology and the cross-section images. The crystallinity of the samples was characterised using X-ray diffraction (XRD, Panalytical X'pert PRO). The structural and selected area electron diffraction (SAED) of the air-annealed undoped and $\mathrm{Al}$-doped $\mathrm{ZnO}$ nanorod arrays was investigated using transmission electron microscopy (TEM; JEOL JEM 3010). The transmittance and absorbance properties of the nanorod arrays were characterised using ultraviolet-visible-nearinfrared (UV-vis-NIR) spectrophotometry (Perkin Elmer Lambda 750). The photoluminescence properties of the prepared samples were characterised using a photoluminescence (PL) spectrometer (Horiba Jobin Yvon 79 DU420A-OE-325) equipped with a helium-cadmium (He-Cd) laser excitation source at $325 \mathrm{~nm}$. The current-voltage $(I-V)$ characteristics of the UV photoconductive sensors were investigated using a two-probe $I$ - $V$ measurement system (Keithley 2400). The 
UV photoresponse measurements of the fabricated sensor were conducted using a UV photocurrent measurement system (Keithley 2400) operating at $365 \mathrm{~nm}$ with a power density of $750 \mu \mathrm{W} / \mathrm{cm}^{2}$ at a bias voltage of $10 \mathrm{~V}$.

\section{Results and Discussion}

Figures 1(a)-1(d) present the FESEM images of the as-grown, oxygen-annealed, air-annealed, and vacuumannealed $\mathrm{Al}$-doped $\mathrm{ZnO}$ nanorod arrays prepared using the sonicated sol-gel immersion method. These images reveal that the nanorods were uniformly deposited on the glass substrate coated with the seed layer after immersion for $50 \mathrm{~min}$. The FESEM images also reveal that the morphology of the Al-doped $\mathrm{ZnO}$ nanorod arrays did not exhibit a significant change after annealing in different environments. Based on the FESEM images, the average diameter of the Al-doped $\mathrm{ZnO}$ nanorod is approximately $60 \mathrm{~nm}$. According to the EDS spectrum of as-grown $\mathrm{Al}$-doped $\mathrm{ZnO}$ nanorod arrays shown in Figure 1(e), the peaks of $\mathrm{Zn}, \mathrm{Al}$, and $\mathrm{O}$ correspond to an atomic ratio of $49.21: 0.64: 50.16$. Figures $2(a)-2(d)$ show the cross-sectional images of the $\mathrm{Al}$-doped $\mathrm{ZnO}$ nanorod arrays that were annealed under different environments. These images indicated that the Al-doped $\mathrm{ZnO}$ nanorods were deposited perpendicular to the substrate with good alignment. The thicknesses of these films were estimated from the FESEM images to be approximately $600 \mathrm{~nm}$.

Figure 3 presents the XRD patterns of the as-grown, oxygen-annealed, air-annealed, and vacuum-annealed Aldoped $\mathrm{ZnO}$ nanorod arrays. The nanorod arrays present diffraction peaks that can be indexed to the $\mathrm{ZnO}$ hexagonal phase with a wurtzite structure (Joint Committee on Powder Diffraction Standards (JCPDS) PDF number 36-1451). The XRD patterns reveal that the (002) peak of the nanorod is the most prevalent, which indicates that the nanorod preferentially grows along the $c$-axis (perpendicular to the substrate). The other weak diffraction peaks in the XRD patterns may be a result of imperfect nanorod alignment on the substrate [37]. According to this result, the relative intensities of the XRD peak from the (002) plane are oxygen-annealed $>$ airannealed > vacuum-annealed > as-grown. This ordering indicates that oxygen is a better annealing environment than the other annealing environments (i.e., air and vacuum) for improving the crystallinity of the $\mathrm{Al}$-doped $\mathrm{ZnO}$ nanorod arrays. Annealing in oxygen promotes the reaction between oxygen and the $\mathrm{Zn}$ interstitials to form crystalline $\mathrm{ZnO}$. Similarly, this process also occurred during annealing in air. However, due to the higher concentration of oxygen molecules in the oxygen-annealing process relative to air annealing, the oxidation rate in oxygen annealing is much faster due to the greater reduction in the free-surface energy. Therefore, the crystallinity of the oxygen-annealed nanorod arrays is better than that of the air-annealed nanorod arrays. The as-grown sample presented low-intensity XRD peaks, which were attributed to the high density of defects in the nanorod arrays, particularly the presence of hydroxyl $(\mathrm{OH})$ groups on the nanorod surface. The presence of $\mathrm{OH}$ groups on the surface of the nanorod is commonly reported for lowtemperature solution-based syntheses $[29,38,39]$. However, the XRD pattern of the vacuum-annealed $\mathrm{ZnO}$ nanorod array presents the weakest peak intensity compared to the other annealed samples. In addition, the XRD pattern of the vacuum-annealed nanorod arrays shows the emergence of $\mathrm{Zn}$ metal peaks. This condition could be attributed to the desorption of $\mathrm{OH}$ groups from the $\mathrm{ZnO}$ nanorod array during annealing, which leaves a large amount of $\mathrm{Zn}$ or $\mathrm{Zn}$ interstitials in the nanorod. Because of the unavailability of oxygen molecules, the oxidation of $\mathrm{Zn}$ could not occur during the annealing process in the vacuum. As a result, the growth of $\mathrm{ZnO}$ was inhibited while maintaining a high concentration of $\mathrm{Zn}$ or $\mathrm{Zn}$ interstitials, thereby degrading the crystallinity of the $\mathrm{Al}$-doped $\mathrm{ZnO}$ nanorod arrays.

Figure 4(a) shows the transmittance spectra of the Aldoped $\mathrm{ZnO}$ nanorod arrays prepared at different annealing environments in the wavelength ranges from 300 to $1500 \mathrm{~nm}$. These spectra demonstrate that the nanorod arrays have good optical transmittance in the visible (400-800 nm) and near-infrared ranges $(800-1500 \mathrm{~nm})$. The spectra also reveal that upon the annealing process in the oxygen environment, the transmittance of the nanorod arrays improves relative to the as-grown sample. Note that the average transmittance of the as-grown $\mathrm{Al}$-doped $\mathrm{ZnO}$ nanorod arrays in the visible region is approximately $72 \%$. The average transmittance of the oxygen-annealed Al-doped $\mathrm{ZnO}$ nanorod arrays in the visible region was estimated to be $78 \%$. However, the transmittance slightly decreased after annealing in air and vacuum, with average transmittances of 77 and $76 \%$, respectively. We also observed that interference fringes appeared in the spectra, which indicated that the nanorod arrays are uniformly deposited on the substrate [40]. Figure 4(b) shows the absorbance spectra of the $\mathrm{Al}$-doped $\mathrm{ZnO}$ nanorod arrays prepared using different annealing environments. The absorbance spectra reveal that all of the samples exhibit good UV absorption properties below $400 \mathrm{~nm}$ with an absorption edge of $380 \mathrm{~nm}$. The sharp absorption edge observed at approximately $380 \mathrm{~nm}$ corresponds to the direct transition of electrons between the edges of the valence band and the conduction band. The high absorption properties in the UV region indicate that the prepared samples are suitable for UV photoconductive sensor applications.

Figure 5 shows the PL spectra of the as-grown, oxygenannealed, air-annealed, and vacuum-annealed Al-doped $\mathrm{ZnO}$ nanorod arrays. Two emission peaks were detected in the PL measurement, located in the UV region and the visible region. The UV emission is due to the recombination of excitons, whereas the visible emission is caused by the emission of defects [41-43]. The as-grown nanorod arrays have a broad and low-intensity UV emission peak centred at $383 \mathrm{~nm}$ and a high-intensity visible emission peak centred at $573 \mathrm{~nm}$. This visible peak is due to the high concentration of $\mathrm{OH}_{-}$ groups on the nanorod surface [44]. For the oxygen-annealed nanorod arrays, the intensity of the UV emission peak that is centred at $379 \mathrm{~nm}$ increased relative to that of the asgrown nanorod arrays. However, the visible region exhibits a reduced intensity and shift to a higher wavelength. This visible emission peak was shifted to $630 \mathrm{~nm}$ and attributed to interstitial oxygen or excess oxygen at the nanorod surface $[39,45]$. The oxygen adsorption in the nanorod arrays 


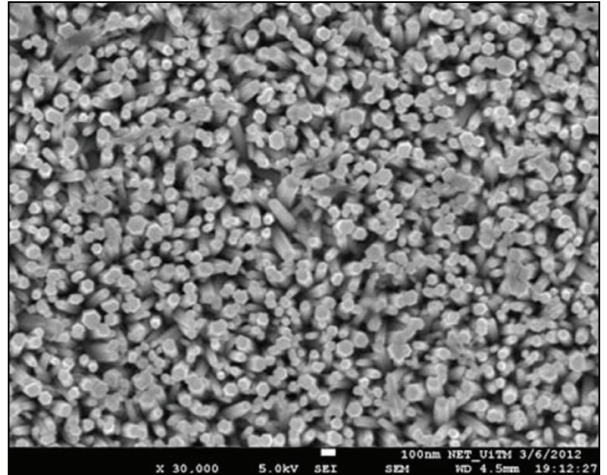

(a)

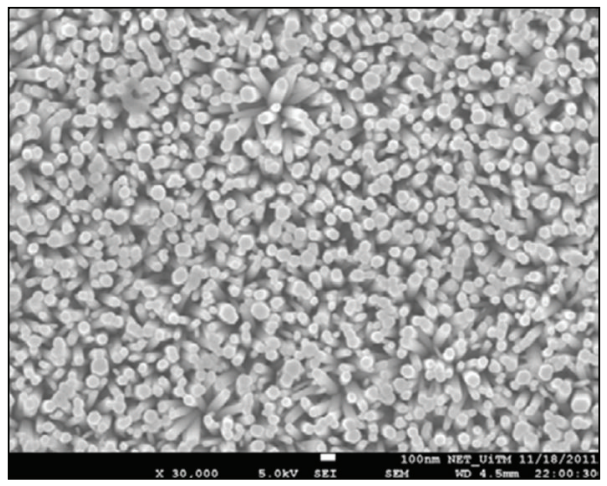

(c)

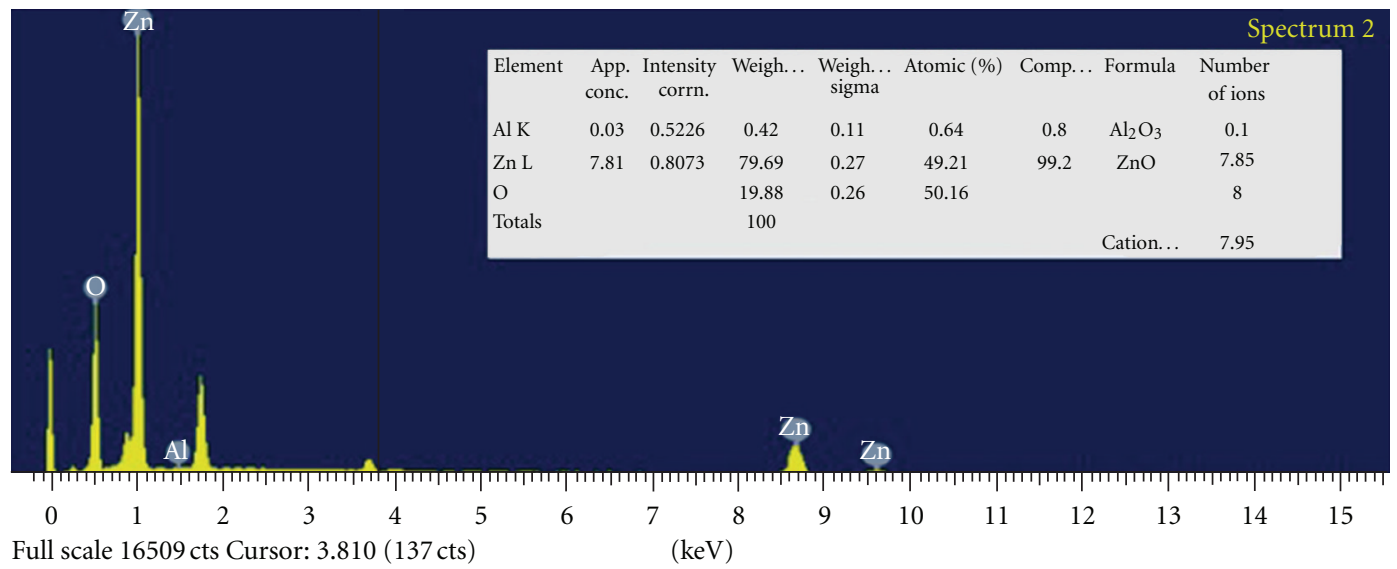

(e)

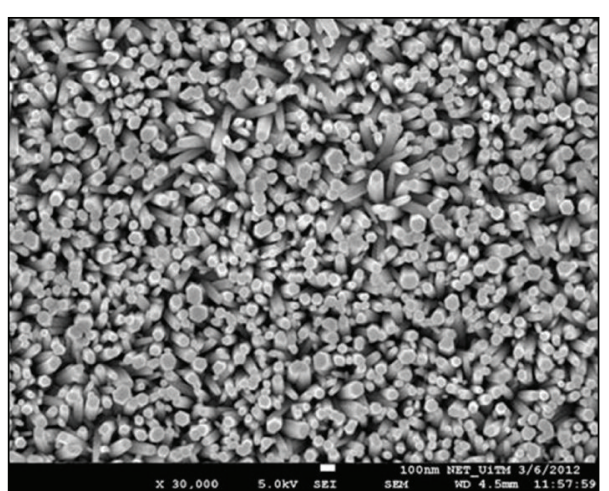

(b)

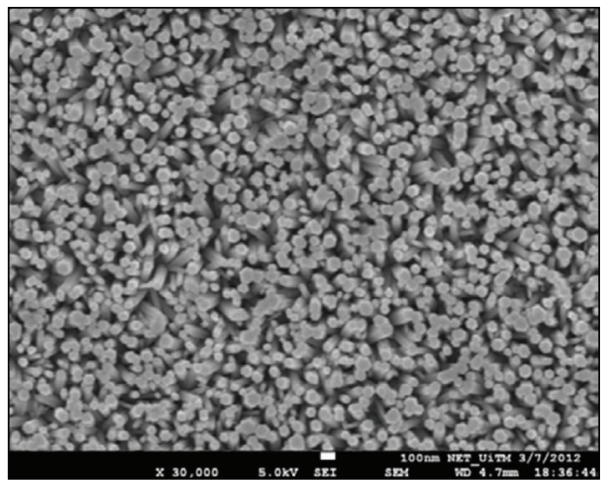

(d)

Figure 1: Surface morphology of (a) as-grown, (b) oxygen-annealed, (c) air-annealed, and (d) vacuum-annealed Al-doped $\mathrm{ZnO}$ nanorod arrays. (e) EDS spectrum of as-grown Al-doped $\mathrm{ZnO}$ nanorod arrays.

also decreases the excitonic recombination, as reported by other groups [39, 46]. However, the air-annealed and vacuum-annealed nanorod arrays show almost identical UV emission peak intensity of the peaks that are centred at 379 and $380 \mathrm{~nm}$, respectively, but slightly different intensities in the visible emission peak. The visible emission peak intensity for the air-annealed nanorod arrays was slightly higher than that of the vacuum-annealed nanorod arrays. In addition, these visible emission peak centres for the airannealed and vacuum-annealed $\mathrm{Al}$-doped $\mathrm{ZnO}$ nanorod arrays are located at different wavelengths of $600 \mathrm{~nm}$ and
$588 \mathrm{~nm}$, respectively. We suspected that this condition is due to different defect conditions, which affected the visible emission of the nanorod arrays. For the air-annealed sample, the defect state may be dominated by oxygen adsorption, but with lower concentration compared to the oxygenannealed nanorod arrays, whereas for the vacuum-annealed sample, the zinc interstitials and oxygen vacancies may be the prominent defects in the nanorod arrays.

Figure 6 presents the $I-V$ measurement spectra of the $\mathrm{Al}$-doped $\mathrm{ZnO}$ nanorod arrays annealed in different environments. The $I-V$ curves indicate that all of the prepared 


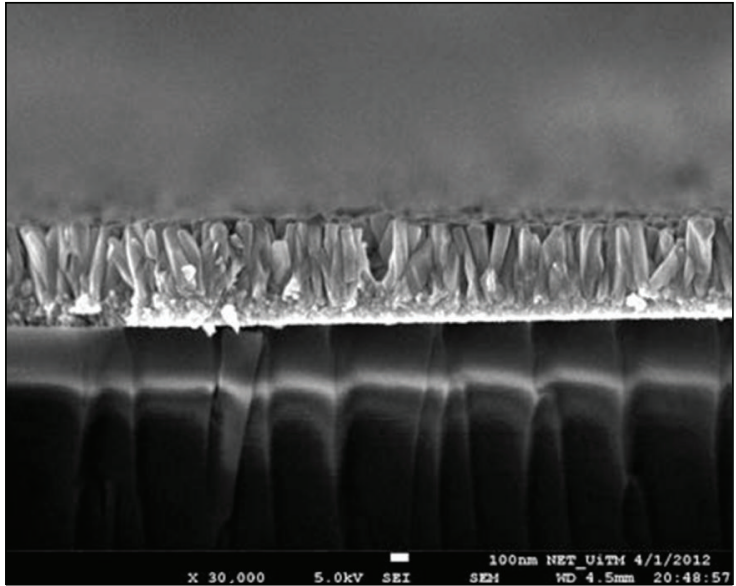

(a)

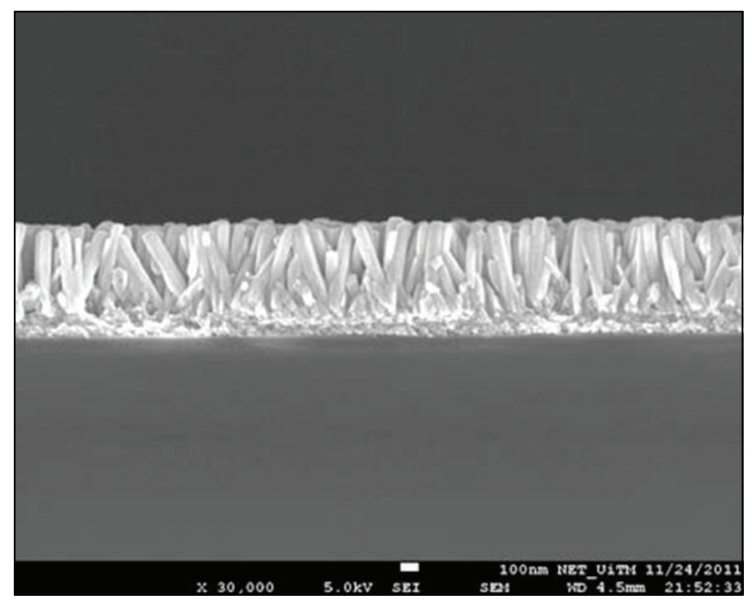

(c)

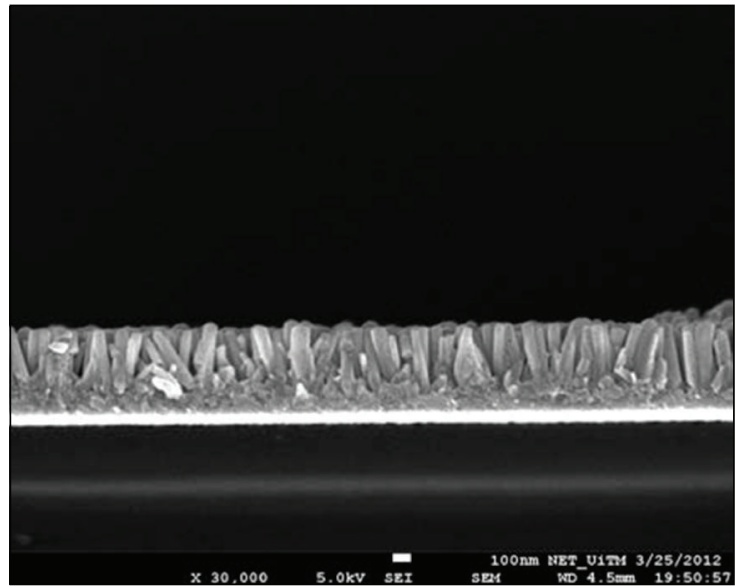

(b)

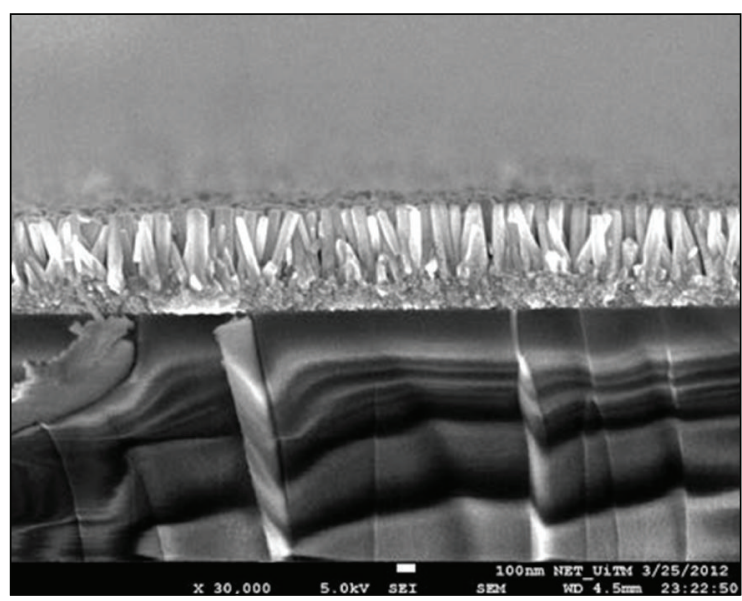

(d)

FIGURE 2: Cross-sectional images of (a) as-grown, (b) oxygen-annealed, (c) air-annealed, and (d) vacuum-annealed Al-doped ZnO nanorod arrays.

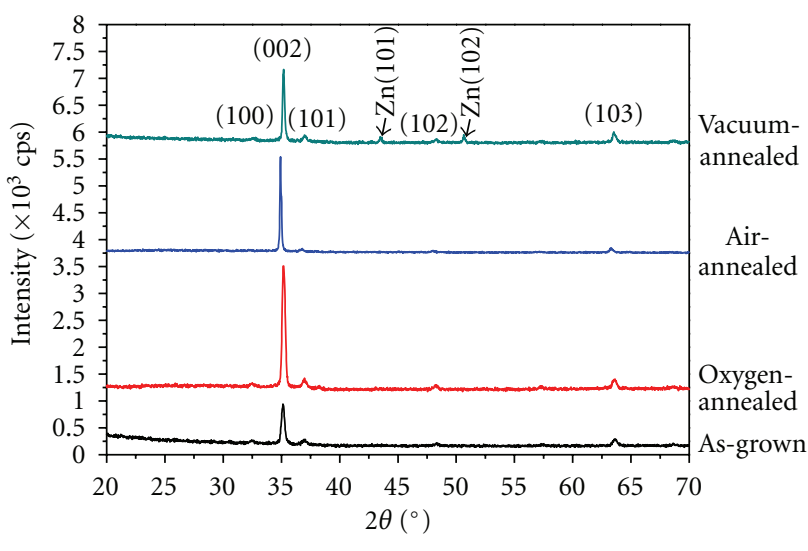

FIGURE 3: XRD patterns of the as-grown, oxygen-annealed, airannealed, and vacuum-annealed $\mathrm{Al}$-doped $\mathrm{ZnO}$ nanorod arrays.

Al-doped $\mathrm{ZnO}$ nanorod arrays formed ohmic contacts with the $\mathrm{Al}$ contacts. However, the current with respect to the supplied voltage shows different values for the as-grown, oxygen-annealed, air-annealed, and vacuum-annealed Aldoped $\mathrm{ZnO}$ nanorod arrays. According to this spectra, the highest current value is exhibited by the vacuumannealed sample, followed by the air-annealed sample, then by the as-grown sample, and finally, by the oxygen-annealed sample. From these results, the resistance of the samples were calculated to be $0.80,1.59,0.16$, and $0.10 \mathrm{M} \Omega$ for the as-grown, oxygen-annealed, air-annealed, and vacuumannealed $\mathrm{Al}$-doped $\mathrm{ZnO}$ nanorod arrays, respectively. The lowest resistance of the vacuum-annealed nanorod arrays might be a result of the excess of free carriers due to the $\mathrm{Zn}$ interstitials and Al-doping. In addition, annealing in vacuum also removed the adsorbed oxygen on the nanorod surface, which decreased the resistance of the nanorod arrays [47]. However, annealing in oxygen significantly increased the resistance of the nanorod arrays, which is likely due to the large amount of oxygen adsorbed on the surface of the nanorod arrays. During the annealing process in oxygen, oxygen could also diffuse into the nanorod arrays, which induces a high density of acceptor-like defects (i.e., Zn vacancies, oxygen antisites) [48]. This condition results in 


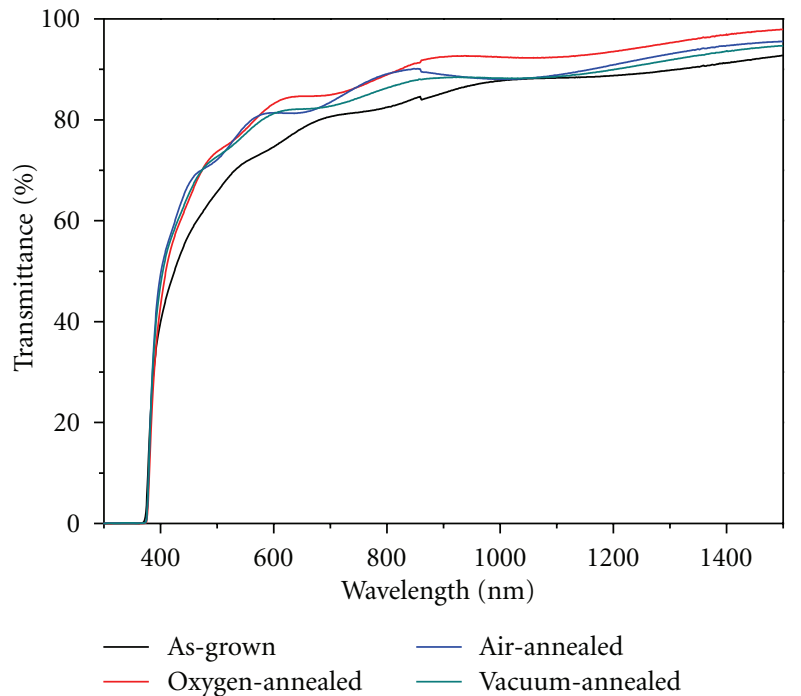

(a)

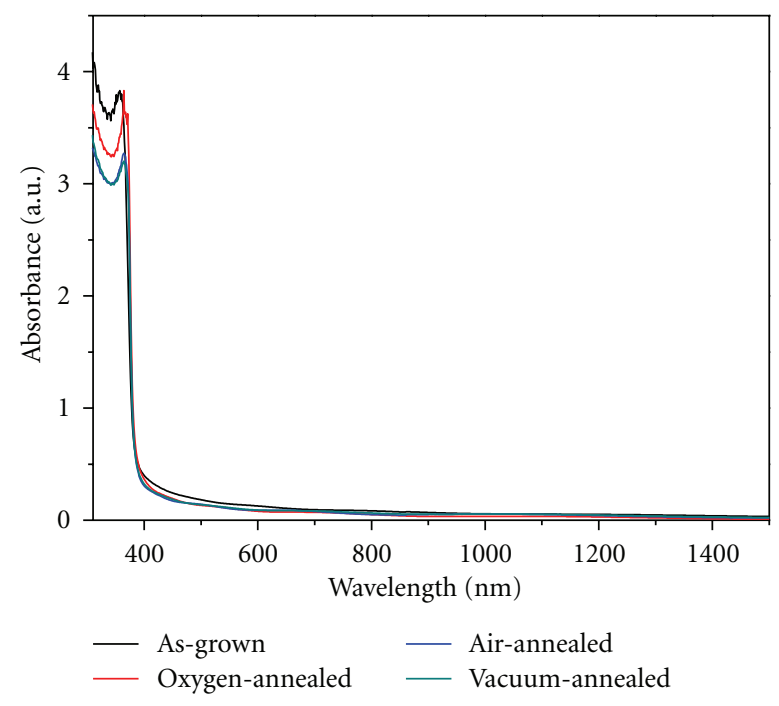

(b)

Figure 4: (a) Transmittance and (b) absorbance spectra of the as-grown and annealed Al-doped ZnO nanorod arrays.

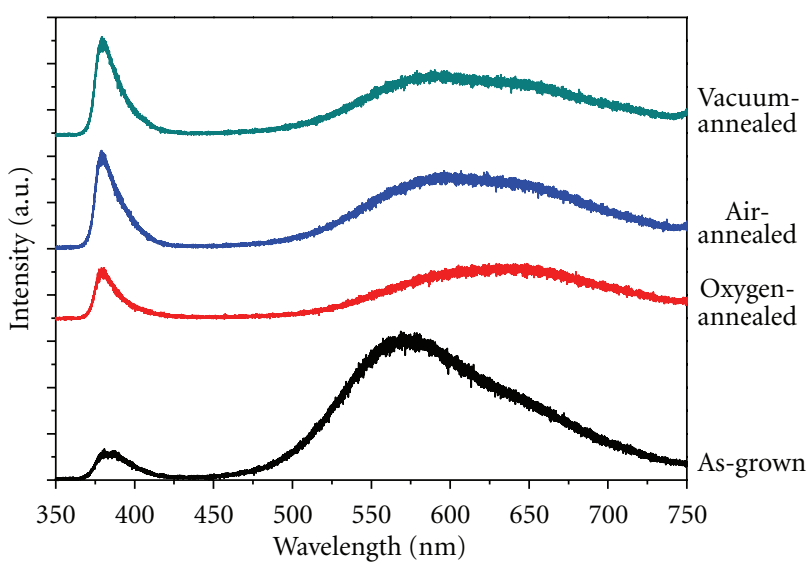

FIGURE 5: Room temperature PL spectra of the as-grown, oxygenannealed, air-annealed, and vacuum-annealed Al-doped $\mathrm{ZnO}$ nanorod arrays.

the compensation of donor-like defects (i.e., oxygen vacancies, $\mathrm{Zn}$ interstitials) and depletion of the carrier density. Meanwhile, annealing the nanorod arrays in air produced the nanorod arrays with a moderate resistance, in which the resistance value was between that of the vacuum-annealed and oxygen-annealed nanorod arrays. This phenomenon is due to the decreased concentration of oxygen molecules in air compared to the concentration of oxygen molecules available during the oxygen annealing process, which reduces the amount of adsorbed oxygen. The as-grown sample presented the highest resistance due to its high defect concentrations and poor crystallinity properties, as shown in the XRD patterns.

Figure 7 depicts the time-resolved photoresponse of the UV photoconductive sensor prepared using the Al-doped $\mathrm{ZnO}$ nanorod arrays that were annealed in different environments. The measurements were performed using $365 \mathrm{~nm}$

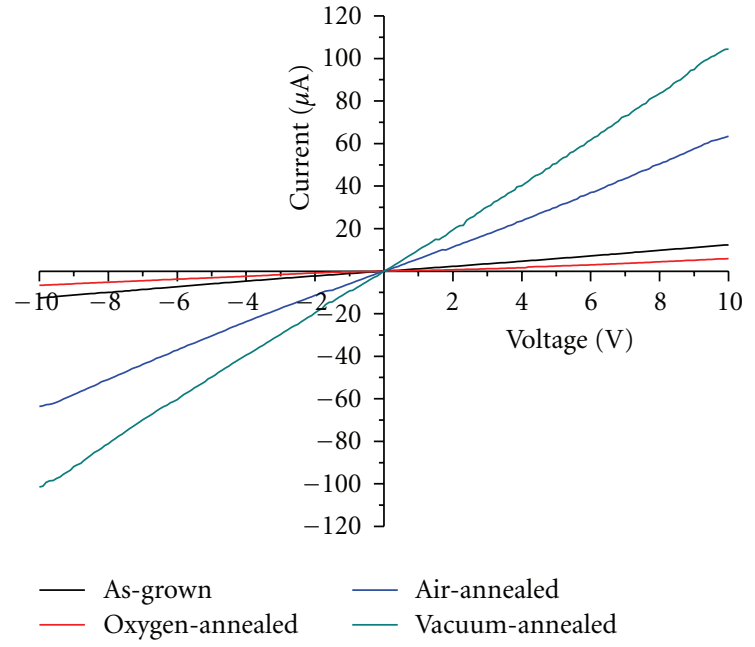

Figure 6: Current-voltage $(I-V)$ plots of the as-grown, oxygenannealed, air-annealed, and vacuum-annealed Al-doped $\mathrm{ZnO}$ nanorod arrays.

UV light with an optical power density of $750 \mu \mathrm{W} / \mathrm{cm}^{2}$ at a bias voltage of $10 \mathrm{~V}$. Under UV illumination, the Al-doped $\mathrm{ZnO}$ nanorod-array-based UV photoconductive sensor showed good photoresponses; the current rapidly increased and then gradually became saturated. The current suddenly decreased when the UV illumination was turned off, eventually returning to its initial value.

The spectra indicate that the photocurrent properties of the sensors provide different responses with the use of Aldoped $\mathrm{ZnO}$ nanorod arrays that were annealed in different environments. The spectra reveal that the UV photoconductive sensor with the vacuum-annealed Al-doped $\mathrm{ZnO}$ nanorod arrays has the highest photocurrent value of $2.43 \times 10^{-4} \mathrm{~A}$. The UV photoconductive sensor that uses 


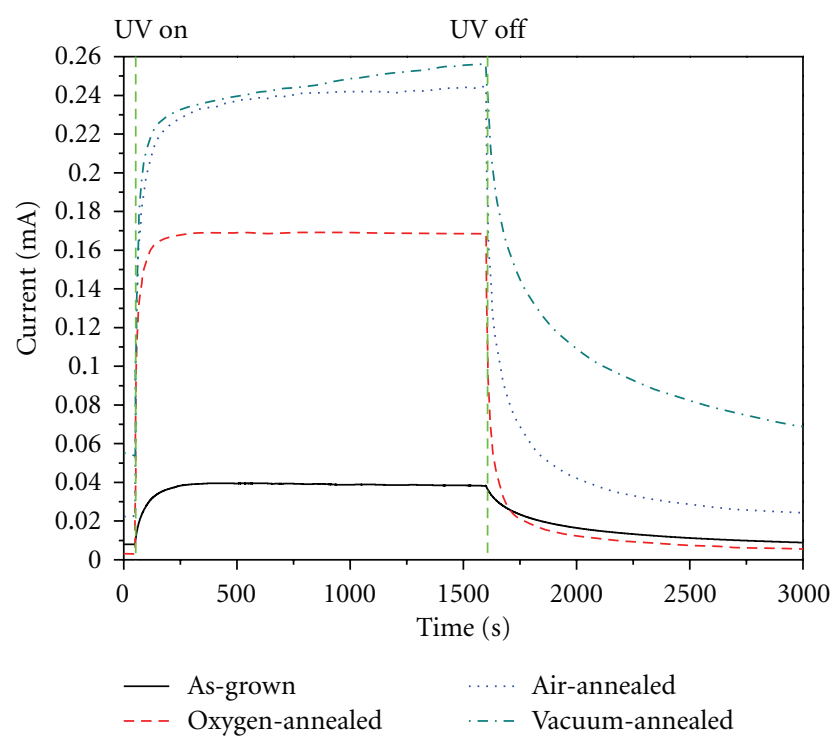

FIGURe 7: Photoresponse spectra of the UV photoconductive sensor using as-grown, oxygen-annealed, air-annealed, and vacuumannealed $\mathrm{Al}$-doped $\mathrm{ZnO}$ nanorod arrays under UV illumination $\left(365 \mathrm{~nm}, 750 \mu \mathrm{W} / \mathrm{cm}^{2}\right)$ and a $10 \mathrm{~V}$ bias.

the air-annealed nanorod arrays also has a high photocurrent value $\left(2.39 \times 10^{-4} \mathrm{~A}\right)$ but it is slightly lower than that of the vacuum-annealed nanorod-arrays. However, the photocurrent value of the oxygen-annealed $\mathrm{Al}$-doped $\mathrm{ZnO}$ nanorodarray-based UV photoconductive sensor was significantly reduced to $1.69 \times 10^{-4} \mathrm{~A}$. Furthermore, the as-grown $\mathrm{Al}$ doped $\mathrm{ZnO}$ nanorod array-based UV photoconductive sensor shows the lowest photocurrent value of $3.91 \times 10^{-5} \mathrm{~A}$. The highest photocurrent value of the vacuum-annealed Al-doped $\mathrm{ZnO}$ nanorod-array-based UV photoconductive sensor could be attributed to the high concentration of $\mathrm{Zn}$ interstitials. According to Bera et al., when $\mathrm{ZnO}$ nanowires with a high concentration of $\mathrm{Zn}$ interstitials are irradiated with UV light, the photogenerated excitons could interact with the $\mathrm{Zn}$ interstitials, which results in ionisation of $\mathrm{Zn}$ interstitials [13]. When $\mathrm{Zn}$ interstitials are ionised, more free electrons are generated in the conduction band, which increases the photocurrent of the sensor. We also proposed that the photogenerated excitons also interact with $\mathrm{Al}$ doping level to contribute more free electrons to the conduction band. However, annealing in air and oxygen results in an improvement of the $\mathrm{ZnO}$ stoichiometry, thereby decreasing the concentration of defects, including $\mathrm{Zn}$ interstitials. During the annealing process, vacant sites in the $\mathrm{ZnO}$ lattice, which resulted from the evaporation of $\mathrm{OH}$ groups from the nanorod surface, were immediately replaced by oxygen from the environment. Because of the excessive oxygen flow during the oxygen annealing process, oxygen molecules are easily adsorbed onto the nanorod surface, which results in the increase of the nanorod resistance. As a result, the photocurrents of the Al-doped $\mathrm{ZnO}$ nanorod array-based UV photoconductive sensors were reduced after annealing in air and oxygen. For the as-grown $\mathrm{Al}$-doped $\mathrm{ZnO}$ nanorodarray-based UV photoconductive sensor, the photocurrent is low because of the low concentration of photogenerated electrons in the conduction band. This condition is a result of the large concentration of $\mathrm{OH}$-groups on the nanorod surface, which hinders efficient photogeneration during UV illumination. In addition, the as-grown nanorod arrays have a large number of structural defects, which is evident by the less intense XRD peaks compared to the annealed samples. This condition reduces the mobility of the nanorod arrays and induced the recombination of the photogenerated electrons with the defects, which decreased the number of photogenerated electrons in the conduction band.

Generally, the adsorption of oxygen on the nanorod surface causes the existence of a non-conductive barrier or a surface depletion region and thus, an upward band bending. However, the width of this barrier in nanorod arrays may differ after annealing in oxygen, air, and vacuum. According to our results, the band bending of the as-grown Al-doped $\mathrm{ZnO}$ nanorod arrays and the $\mathrm{Al}$-doped $\mathrm{ZnO}$ nanorod arrays that were annealed in oxygen, air, and vacuum can be illustrated in Figure 8. In this case, among the annealed samples, the oxygen-annealed $\mathrm{Al}$-doped $\mathrm{ZnO}$ nanorod arrays have the most depleted surface region due to the large amount of adsorbed oxygen, followed by the air-annealed sample and the vacuum-annealed sample. For this reason, the oxygen-annealed $\mathrm{Al}$-doped $\mathrm{ZnO}$ nanorod arrays have lower photocurrent properties compared to the other annealed samples. This theory was also supported by our PL measurement result, in which the UV emission was suppressed and has lower intensity compared to the other annealed samples despite the oxygen-annealed nanorod arrays having the highest crystallinity. Meanwhile, for the as-grown nanorod arrays, the depletion region is primarily attributed to the $\mathrm{OH}$-groups and other native defects of $\mathrm{ZnO}$, such as oxygen vacancies and $\mathrm{Zn}$ interstitials.

From the photocurrent spectra, the responsivity of the sensors was estimated using the following equation [49]:

$$
R=\frac{I_{\mathrm{ph}}-I_{\mathrm{dark}}}{P_{\mathrm{op}}}
$$

where $I_{\mathrm{ph}}$ is the photocurrent, $I_{\text {dark }}$ is the dark current, and $P_{\text {op }}$ is the optical power of the UV source. In this study, the $I_{\text {dark }}$ values of the sensors fabricated using the as-grown, oxygen-annealed, air-annealed, and vacuum-annealed Aldoped $\mathrm{ZnO}$ nanorods are $6.29 \times 10^{-6}, 3.03 \times 10^{-6}, 2.26 \times$ $10^{-5}$, and $5.44 \times 10^{-5} \mathrm{~A}$, respectively. From this calculation, the responsivity values of the sensors composed of the as-grown, oxygen-annealed, air-annealed, and vacuumannealed $\mathrm{Al}$-doped $\mathrm{ZnO}$ nanorods are $0.73,3.69,4.81$, and $4.19 \mathrm{~A} / \mathrm{W}$, respectively. This result indicates that the sensor composed of air-annealed $\mathrm{ZnO}$ nanorod arrays had a higher responsivity than the other samples. Although the photocurrent value of the vacuum-annealed $\mathrm{Al}$-doped $\mathrm{ZnO}$ nanorod-array-based UV sensor is the highest, the sensor exhibits a lower responsivity value than the air-annealed nanorod-based UV photoconductive sensor due to its high dark current value. We believed that this large dark current value of vacuum-annealed $\mathrm{Al}$-doped $\mathrm{ZnO}$ nanorod-arraybased UV photoconductive sensor is primarily contributed 

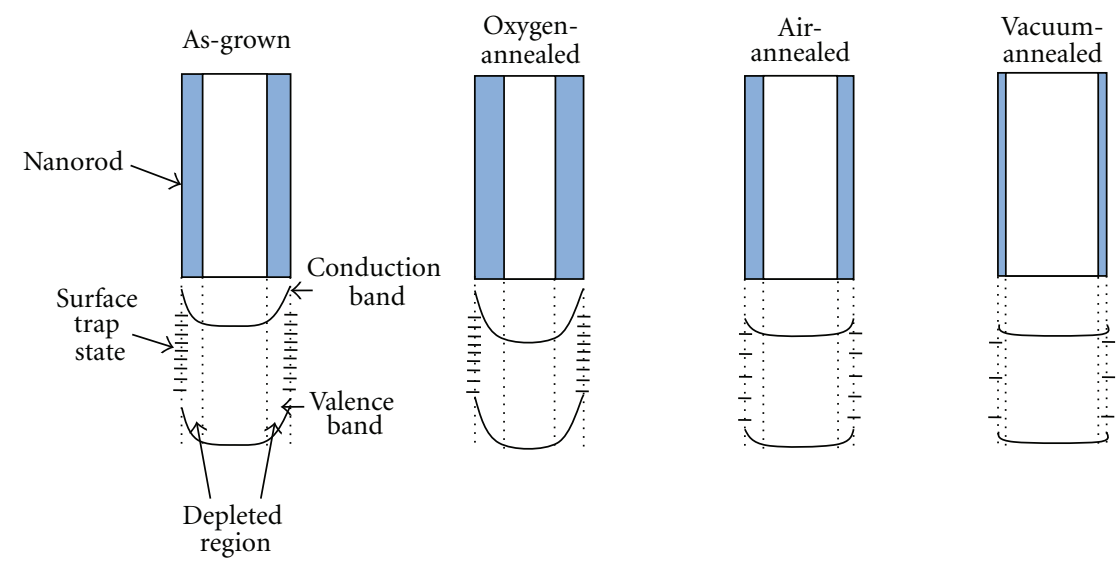

FIGURE 8: Schematic band diagram of the as-grown, oxygen-annealed, air-annealed, and vacuum-annealed Al-doped ZnO nanorod arrays illustrating the band bending due to oxygen adsorption and defects.

to high concentration of $\mathrm{Zn}$ interstitials and Al-doping. This condition improves the conductivity of the sensor, which results in significant enhancement of the dark current than that of the other samples.

The sensitivity of the sensors, which is defined as the photocurrent-to-dark-current ratio, was calculated for all of the devices. The sensitivity values of the sensors composed of the as-grown, oxygen-annealed, air-annealed, and vacuumannealed $\mathrm{Al}$-doped $\mathrm{ZnO}$ nanorod arrays are 6.2, 55.6, 10.6, and 4.6, respectively. The results indicate that the oxygenannealed Al-doped $\mathrm{ZnO}$ nanorod array-based UV photoconductive sensors had the highest sensitivity. The improvement of the sensor sensitivity by oxygen annealing is due to the significant reduction of the dark current value as compared with the other samples. We suspect that the significant reduction in the dark current value is correlated with more adsorbed oxygen on the oxygen-annealed nanorod arrays, which increases the resistance of the film, as shown by the $I-V$ measurement results. In addition, annealing in oxygen improves the surface condition of the nanorod arrays, which increases their affinity for the oxygen molecules. The sensitivity of the sensor has been reported to be correlated with the oxygen adsorption and desorption processes $[12,33$, 50]. In the dark, oxygen molecules tend to adsorb onto the nanorod surfaces by capturing free electrons and producing adsorbed oxygen ions, as shown by the following equation:

$$
\mathrm{O}_{2}+\mathrm{e}^{-} \longrightarrow \mathrm{O}_{2}^{-}
$$

where $\mathrm{O}_{2}$ is the oxygen molecule, $\mathrm{e}^{-}$is the free electron, and $\mathrm{O}_{2}{ }^{-}$is the adsorbed oxygen ion on the nanorod surface. The adsorbed oxygen ions create a barrier near the surface, which generates a low current before UV illumination. When UV light is irradiated onto the nanorods, photogenerated electron-hole pairs are generated at the surface according to the following equation:

$$
\mathrm{hv} \longrightarrow \mathrm{h}^{+}+\mathrm{e}^{-},
$$

where hv is the photon energy of UV light, $\mathrm{h}^{+}$is the photogenerated hole in the valence band, and $\mathrm{e}^{-}$is the photogenerated electron in the conduction band. The photogenerated holes recombine with the adsorbed oxygen ions on the surface, producing oxygen molecules; this reaction also eliminates the barrier near the nanorod surface. This process is described by the following equation:

$$
\mathrm{O}_{2}{ }^{-}+\mathrm{h}^{+} \longrightarrow \mathrm{O}_{2} \text {. }
$$

At the same time, the desorption of adsorbed oxygen ions on the nanorod surface leaves photogenerated electrons in the conduction band, thereby increasing the film conductivity and contributing to the photocurrent. When the UV light is switched off, oxygen once again begins to adsorb onto the nanorod surface, thereby decreasing the conductivity of the sensor.

Using the photocurrent spectra, the rise and decay time constants of the fabricated sensors were calculated using the following equations:

$$
\begin{aligned}
& I= \\
& \quad I_{0}\left[1-\exp \left(-\frac{t}{\tau_{r}}\right)\right]: \text { rise process with UV illumination on, } \\
& I=I_{0} \exp \left(-\frac{t}{\tau_{d}}\right): \text { decay process with UV illumination off, }
\end{aligned}
$$

where $I$ is the magnitude of the current, $I_{0}$ is the saturated photocurrent, $t$ is the time $\tau_{r}$ is the rise time constant, and $\tau_{d}$ is the decay time constant. The calculation results indicate that the sensors constructed using the as-grown, oxygen-annealed, air-annealed, and vacuum-annealed Aldoped $\mathrm{ZnO}$ nanorod arrays have rise (decay) time constants of 38 (109), 3 (13), 10 (26), and 15 (52) s, respectively. Based on these results, it can be concluded that the oxygen-annealed Al-doped $\mathrm{ZnO}$ nanorod array-based UV photoconductive sensor exhibits the fastest response. This behaviour may be attributed to the surface condition of the oxygen-annealed $\mathrm{Al}$-doped $\mathrm{ZnO}$ nanorod arrays, which can promptly adsorb and desorb oxygen during the switching on and off of the UV illumination, thereby resulting in sudden changes in the nanorod resistance. In addition, 


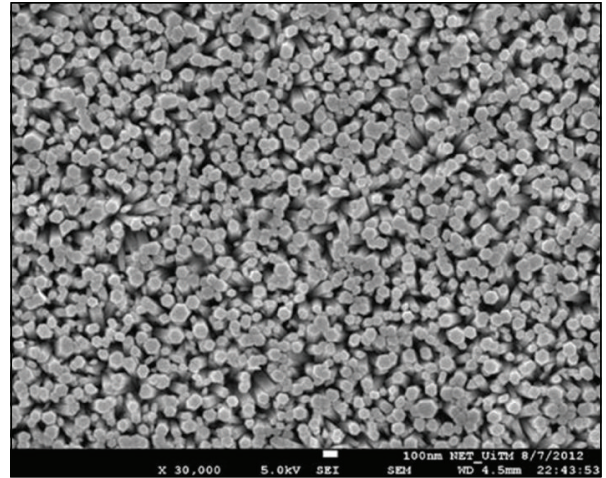

(a)

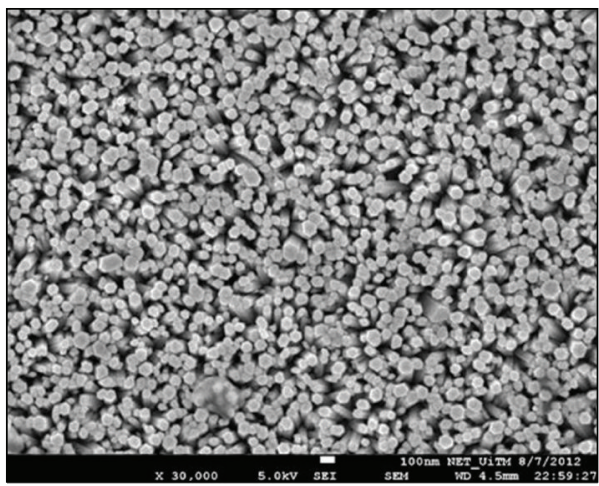

(c)

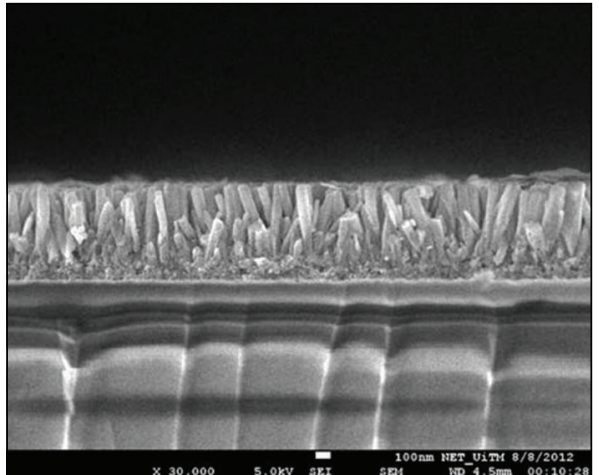

(b)

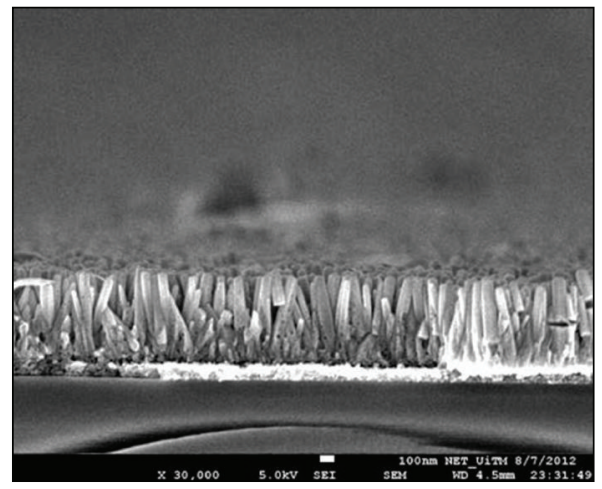

(d)

FIGURE 9: Surface morphology and cross-sectional images of Al-doped ZnO nanorod arrays as a function of immerse time: ((a)-(b)) 100 min and ((c)-(d)) 150 min.

TABLE 1: The characteristics of the as-grown, oxygen-annealed, air-annealed, and vacuum-annealed Al-doped ZnO nanorod-array-based UV photoconductive sensors.

\begin{tabular}{lccccccc}
\hline Sample & $\begin{array}{c}\text { Resistance } \\
(\mathrm{M} \Omega)\end{array}$ & $\begin{array}{c}\text { Dark current } \\
(\mathrm{A})\end{array}$ & $\begin{array}{c}\text { Photocurrent } \\
(\mathrm{A})\end{array}$ & $\begin{array}{c}\text { Rise time } \\
\text { constant }(\mathrm{s})\end{array}$ & $\begin{array}{c}\text { Decay time } \\
\text { constant (s) }\end{array}$ & $\begin{array}{c}\text { Responsivity } \\
(\mathrm{A} / \mathrm{W})\end{array}$ & $\begin{array}{c}\text { Sensitivity } \\
\text { As-grown }\end{array}$ \\
0.80 & $6.29 \times 10^{-6}$ & $3.91 \times 10^{-5}$ & 38 & 109 & 0.73 & 6.2 \\
Oxygen-annealed & 1.59 & $3.03 \times 10^{-6}$ & $1.69 \times 10^{-4}$ & 3 & 13 & 3.69 & 55.6 \\
Air-annealed & 0.16 & $2.26 \times 10^{-5}$ & $2.39 \times 10^{-4}$ & 10 & 26 & 4.81 & 10.6 \\
Vacuum-annealed & 0.10 & $5.44 \times 10^{-5}$ & $2.43 \times 10^{-4}$ & 15 & 52 & 4.19 \\
\hline
\end{tabular}

the oxygen-annealed Al-doped $\mathrm{ZnO}$ nanorod arrays possess better crystallinity than the other samples, which enhances the mobility of the photogenerated carriers in the nanorod arrays. In comparison, the vacuum-annealed nanorod arrays show a higher rise and decay time constant due to the prominent electron trapping at the positively charged $\mathrm{Zn}$ interstitial defect state, which has a large lifetime [51]. The characteristics of the as-grown, oxygen-annealed, airannealed, and vacuum-annealed Al-doped $\mathrm{ZnO}$ nanorodarray-based UV photoconductive sensors are presented in Table 1.

We also investigate the UV photoconductive sensors performance using air-annealed $\mathrm{Al}$-doped $\mathrm{ZnO}$ nanorod arrays that were prepared for longer immersion times of 100 and $150 \mathrm{~min}$. Figures $9(\mathrm{a})$ and $9(\mathrm{c})$ show the surface morphologies of air-annealed $\mathrm{Al}$-doped $\mathrm{ZnO}$ nanorod arrays immersed for 100 and 150 min, respectively. In these FESEM images, dense nanorod arrays can be observed with high uniformity across all samples. However, the diameter of the nanorods is almost constant at $60 \mathrm{~nm}$ with further increase of immersion time up to $150 \mathrm{~min}$. Figures 9(b) and 9(d) show the cross-sectional images of air-annealed Al-doped $\mathrm{ZnO}$ nanorod arrays prepared at immersion time of 100 and $150 \mathrm{~nm}$, respectively. Based on the cross-sectional images, the thickness of the film increase, with the increase of immersion time. On the basis of the FESEM measurements, the thicknesses of the films prepared by immersion for 100 and $150 \mathrm{~min}$ are approximately 650 and $700 \mathrm{~nm}$, respectively. Figure 10 depicts $I-V$ curves of Al-doped $\mathrm{ZnO}$ nanorod arrays prepared at different immersion times. The graphs reveal that the current intensity with respect to the voltage decrease when the immersion time was increased up to 


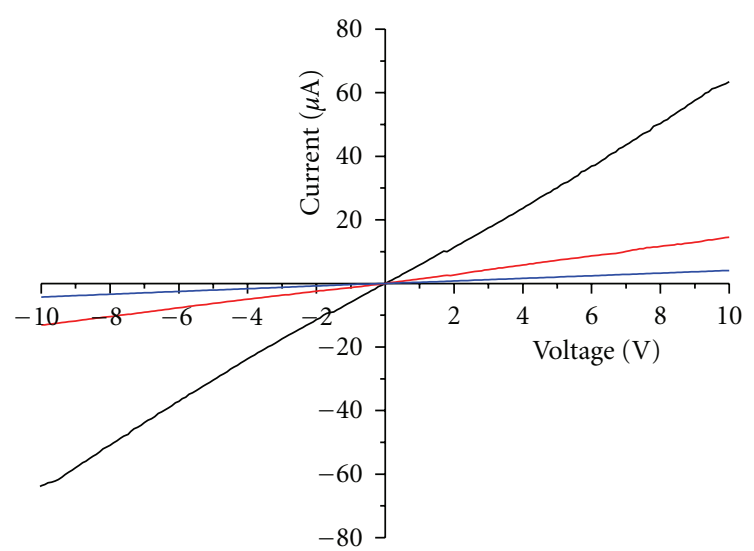

$\begin{array}{ll}- & 50 \mathrm{~min} \\ - & 100 \mathrm{~min} \\ - & 150 \mathrm{~min}\end{array}$

Figure 10: The $I-V$ characteristic of air-annealed Al-doped $\mathrm{ZnO}$ nanorod arrays prepared for different immersion times.

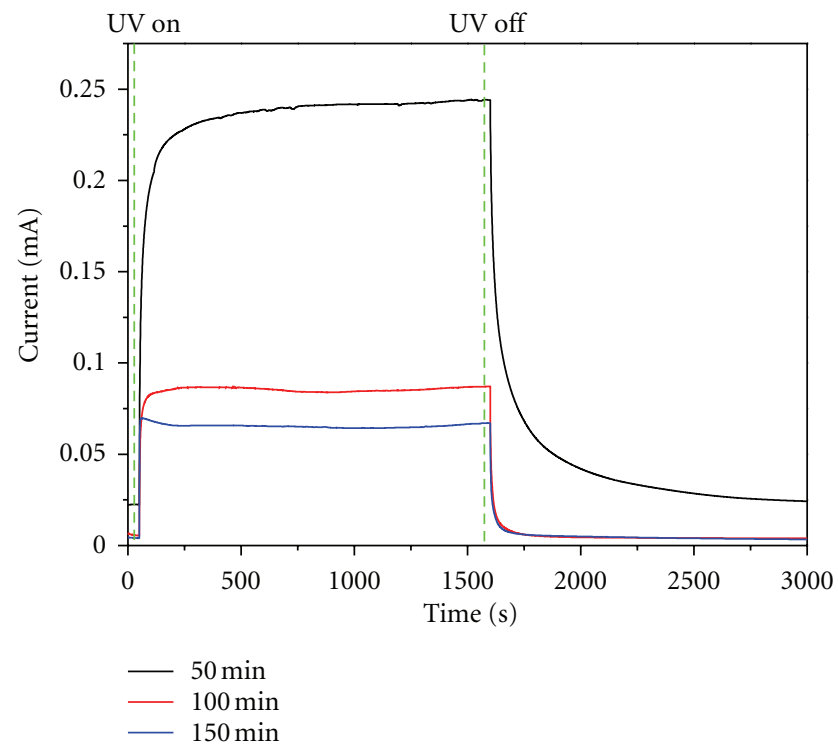

FIgure 11: Photoresponse spectra of the UV photoconductive sensor using air-annealed $\mathrm{Al}$-doped $\mathrm{ZnO}$ nanorod arrays prepared for different immersion times under UV illumination $(365 \mathrm{~nm}$, $750 \mu \mathrm{W} / \mathrm{cm}^{2}$ ) and a $10 \mathrm{~V}$ bias.

$150 \mathrm{~min}$. The resistance of the samples was calculated to be 0.72 and $2.41 \mathrm{M} \Omega$ for the nanorod prepared at immersion time of 100 and $150 \mathrm{~min}$, respectively.

Figure 11 shows the time-resolved photoresponse of the UV photoconductive sensor prepared using the air-annealed $\mathrm{Al}$-doped $\mathrm{ZnO}$ nanorod arrays that were prepared at longer immersion times of 100 and $150 \mathrm{~min}$. The results show that both photocurrent and dark current of the sensors were decreased with the increase of immersion time. The photocurrent/dark current values of the sensors are 8.41 $\times 10^{-5} / 5.43 \times 10^{-6}$ and $6.50 \times 10^{-5} / 4.07 \times 10^{-6} \mathrm{~A}$ for the nanorod arrays prepared for immersion times of 100 and $150 \mathrm{~min}$, respectively. The reduction in photocurrent value for sensors using nanorod arrays prepared for longer time influenced the responsivity of the devices; devices using nanorod arrays prepared for longer immersion time exhibited lower responsivity values. The responsivity values of the sensors are 1.75 and $1.36 \mathrm{~A} / \mathrm{W}$ for the nanorod arrays prepared for immersion times of 100 and $150 \mathrm{~min}$, respectively. In this case, we believed that the decrease of the photocurrent and responsivity values of the devices was affected by the increase of the resistance of the nanorod arrays after being immersed for longer times. However, the sensitivity of the devices is slightly increased using Aldoped $\mathrm{ZnO}$ nanorod arrays immersed for longer times. The sensitivity values of the devices are 15.5 and 16.0 using Aldoped $\mathrm{ZnO}$ nanorod arrays prepared for 100 and $150 \mathrm{~min}$, respectively. This sensitivity increment may be attributed to decrease of the dark current and increase of the surface area for the devices using $\mathrm{Al}$-doped $\mathrm{ZnO}$ nanorod arrays immersed for longer times.

In order to understand the effects of $\mathrm{Al}$ doping on $\mathrm{ZnO}$ nanorod array-based UV photoconductive sensor performance, air-annealed undoped and Al-doped $\mathrm{ZnO}$ nanorod-array-based UV photoconductive sensor were studied. Figure 12(a) shows FESEM image of air-annealed undoped $\mathrm{ZnO}$ nanorod arrays at magnification of 30,000x. The image reveals that undoped $\mathrm{ZnO}$ nanorods have been uniformly deposited on the seed-layer-coated glass substrate. The diameter of the undoped $\mathrm{ZnO}$ nanorod is estimated to be $100 \mathrm{~nm}$, in which the size is larger than that of the air-annealed Al-doped $\mathrm{ZnO}$ nanorod and other samples. A cross-sectional image as shown in Figure 12(b) confirms that the nanorods grew perpendicular to the substrate with the thickness estimated to be approximately $600 \mathrm{~nm}$. Figures 13(a)-13(d) show TEM images and SAED patterns of airannealed undoped and $\mathrm{Al}$-doped $\mathrm{ZnO}$ nanorods. These results indicate that both undoped and $\mathrm{Al}$-doped $\mathrm{ZnO}$ nanorods are single crystals with wurtzite $\mathrm{ZnO}$ structure. The TEM images also reveal that the size of the Aldoped $\mathrm{ZnO}$ nanorod is smaller than the undoped $\mathrm{ZnO}$, which attributed to the effect of the doped $\mathrm{Al}$. The $\mathrm{Al}^{3+}$ ions $(0.054 \mathrm{~nm})$ have smaller ionic radius than $\mathrm{Zn}^{2+}$ ions $(0.074 \mathrm{~nm})$ and it is expected that this ionic radius difference may influence the diameter of $\mathrm{ZnO}$ nanorods when doped with $\mathrm{Al}[52,53]$.

Figure 14 shows the $I-V$ properties of the undoped and Al-doped $\mathrm{ZnO}$ nanorod arrays, which clearly show that the undoped $\mathrm{ZnO}$ nanorod arrays exhibit lower current value than that of $\mathrm{Al}$-doped $\mathrm{ZnO}$ nanorod arrays with respect to the supplied voltage. From this $I-V$ characteristic, the resistance of the undoped arrays was calculated to be $1.15 \mathrm{M} \Omega$. It is understood that this resistance value is higher than resistance value of air-annealed, vacuum-annealed, and as-grown $\mathrm{Al}$-doped $\mathrm{ZnO}$ nanorod arrays but show lower values than that of oxygen-annealed $\mathrm{Al}$-doped $\mathrm{ZnO}$ nanorod arrays.

Figure 15 shows the photoresponse spectra of the airannealed undoped and Al-doped $\mathrm{ZnO}$ nanorod-array-based UV photoconductive sensors. The spectra reveal that both photocurrent and dark current of the undoped $\mathrm{ZnO}$ 


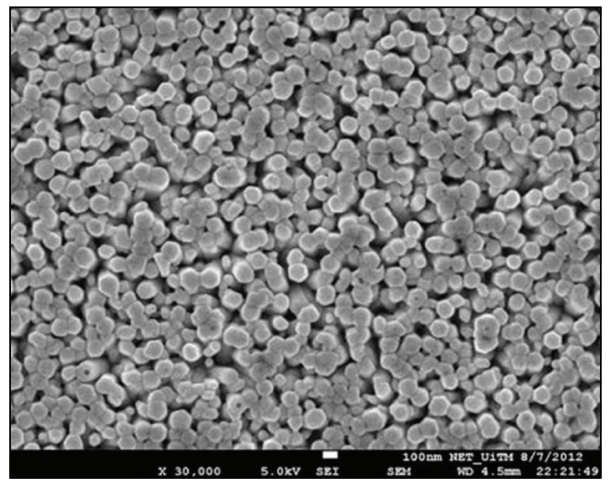

(a)

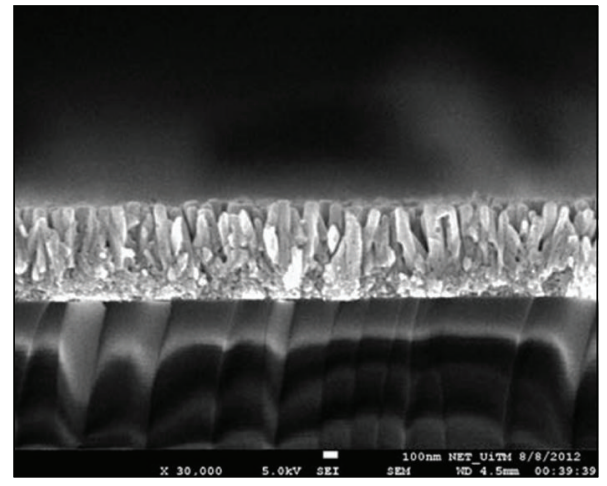

(b)

FIGURE 12: (a) Surface morphology and (b) cross-sectional images of undoped $\mathrm{ZnO}$ nanorod arrays.

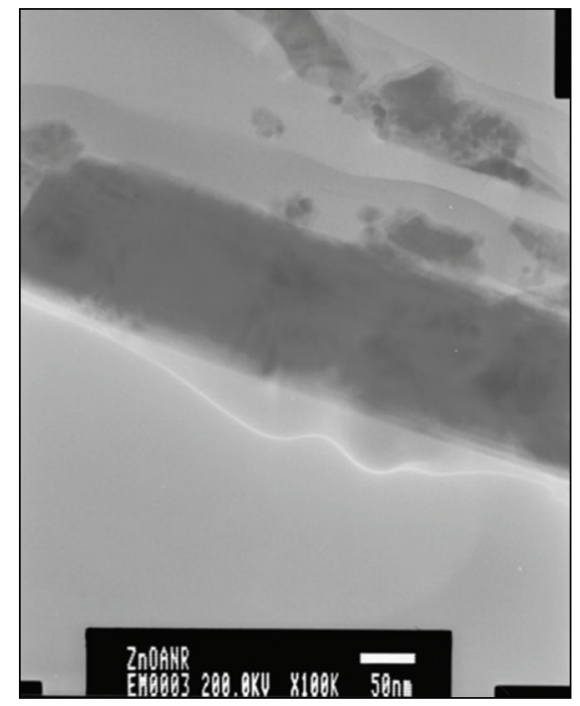

(a)

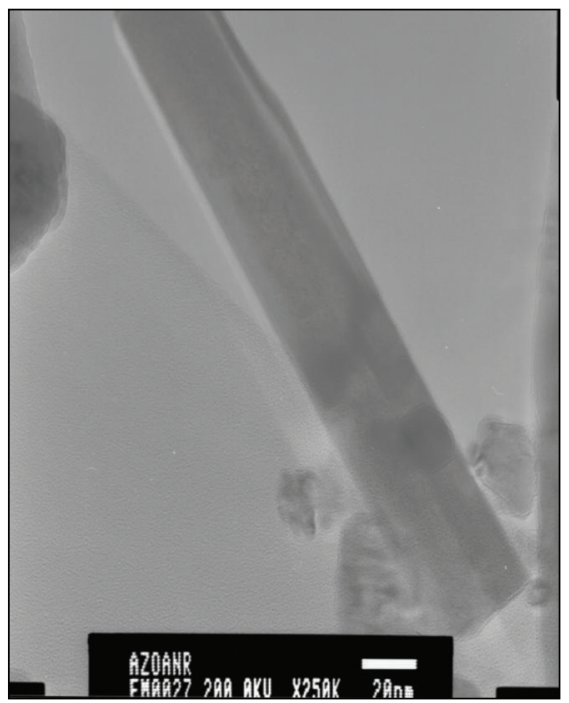

(c)

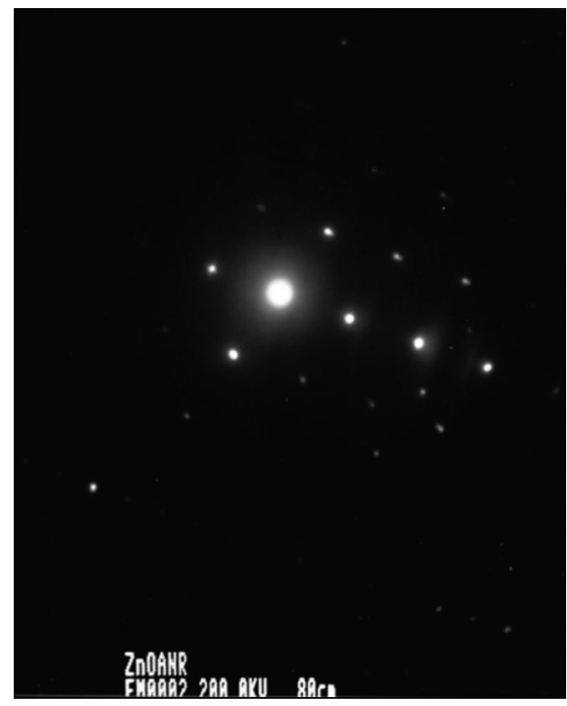

(b)

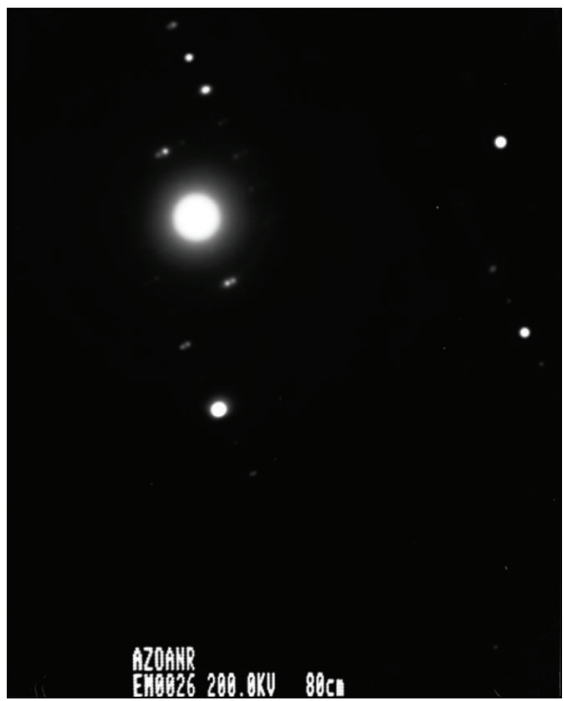

(d)

FIGURE 13: (a) TEM image and (b) SAED pattern of the undoped ZnO nanorod. (c) TEM image and (d) SAED pattern of the Al-doped ZnO nanorod. 


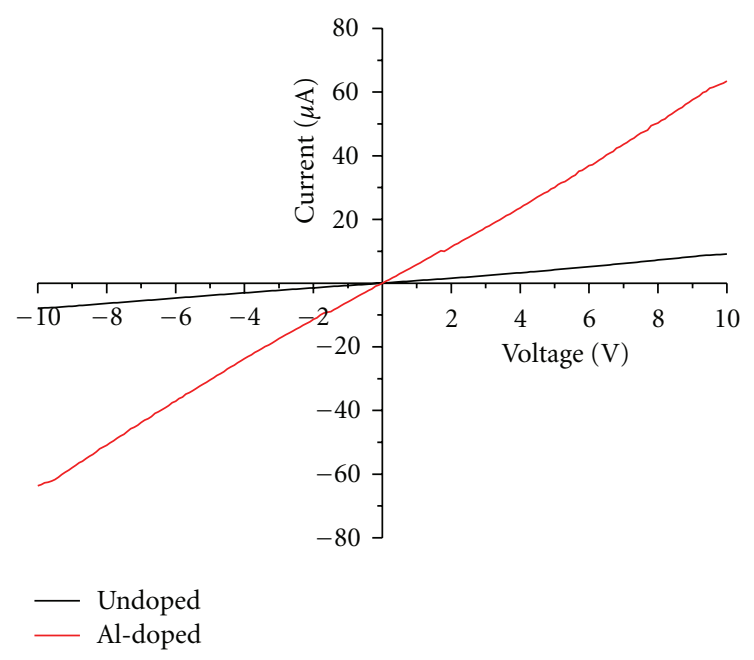

Figure 14: The $I-V$ characteristic of air-annealed undoped and Aldoped $\mathrm{ZnO}$ nanorod arrays.

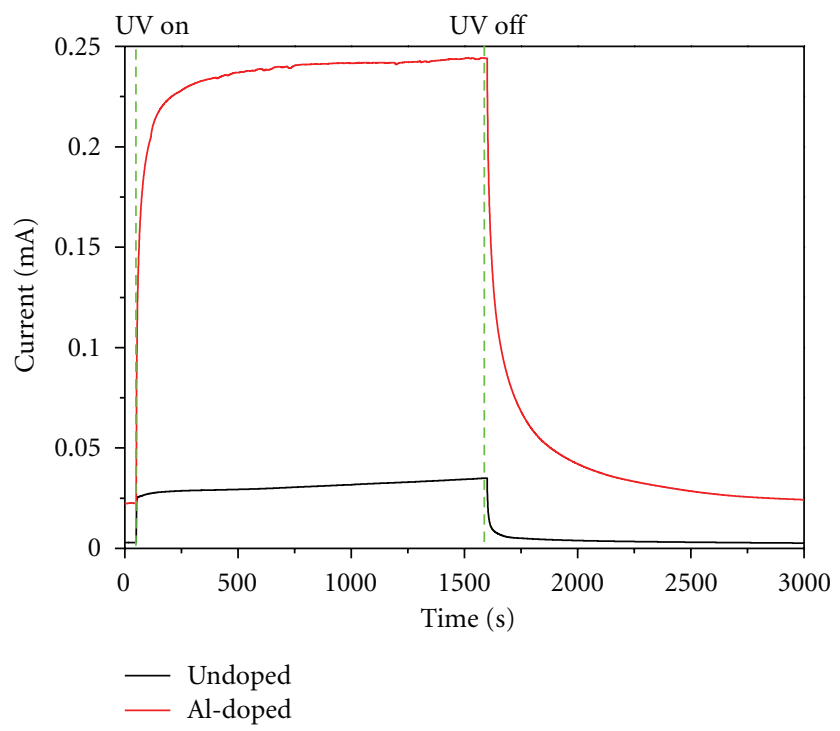

FIGURe 15: Photoresponse of undoped and Al-doped $\mathrm{ZnO}$ nanorod array-based UV photoconductive sensors under UV illumination $\left(365 \mathrm{~nm}, 750 \mu \mathrm{W} / \mathrm{cm}^{2}\right)$ and a $10 \mathrm{~V}$ bias.

nanorod-array-based UV photoconductive sensor show lower values than that of the $\mathrm{Al}$-doped $\mathrm{ZnO}$ nanorod-arraybased UV photoconductive sensor. The photocurrent/ dark current of the device is $2.98 \times 10^{-5} / 2.97 \times 10^{-6} \mathrm{~A}$, while the responsivity and sensitivity values were calculated to be $0.60 \mathrm{~A} / \mathrm{W}$ and 10.0, respectively. When comparing the performance of the undoped and Al-doped $\mathrm{ZnO}$ nanorod-arraybased UV photoconductive sensors (i.e., as-grown, oxygenannealed, air-annealed, and vacuum-annealed Al-doped $\mathrm{ZnO}$ nanorod arrays), the undoped $\mathrm{ZnO}$ nanorod-arraybased device shows the lowest photocurrent and responsivity values. From this result, it can be shown that the doped Al improved the photocurrent and responsivity of the devices by increasing the carrier concentration of the nanorod arrays. When $\mathrm{ZnO}$ is doped with $\mathrm{Al}$, the $\mathrm{Al}^{3+}$ ions substitute the
$\mathrm{Zn}^{2+}$ ions in their sites in $\mathrm{ZnO}$ lattice to generate free electron in the process $[8,54,55]$. This condition increases the carrier concentration of the nanorod arrays and thus, improves the photocurrent and responsivity values of the Al-doped $\mathrm{ZnO}$ nanorod-array-based UV photoconductive sensors. Moreover, this phenomenon could also attributed to the higher surface to volume ratio of $\mathrm{Al}$-doped $\mathrm{ZnO}$ nanorod-arrays compared to the undoped $\mathrm{ZnO}$, which is contributed by smaller size of the $\mathrm{Al}$-doped $\mathrm{ZnO}$ nanorod as can be observed in the FESEM and TEM images in Figures 12 and 13, respectively. Besides that, the doped $\mathrm{Al}$ was also reported to increase the stability and performance of the UV photoconductive sensor by decreasing the defect incident in $\mathrm{ZnO}$ such as $\mathrm{Zn}$ interstitials and oxygen vacancies $[8,56]$. On the other hand, the sensitivity value of the undoped $\mathrm{ZnO}$ nanorod array-based UV photoconductive sensor was greater than that of the as-grown and vacuumannealed $\mathrm{Al}$-doped $\mathrm{ZnO}$ nanorod array-based devices but lower than that of air-annealed and oxygen-annealed Aldoped $\mathrm{ZnO}$ nanorod array-based UV photoconductive sensor. We believed that this condition is mainly attributed to the low dark current value of the undoped $\mathrm{ZnO}$ nanorod array-based UV photoconductive sensor, which increases the sensitivity value compared to that of the as-grown and vacuum-annealed $\mathrm{Al}$-doped $\mathrm{ZnO}$ nanorod array-based devices. However, the undoped $\mathrm{ZnO}$ nanorod arrays lack free electron, which lower the photocurrent value of the device. As a result, the sensitivity of the undoped $\mathrm{ZnO}$ nanorod array-based UV photoconductive sensor is lower than that of the air-annealed and oxygen-annealed Al-doped $\mathrm{ZnO}$ nanorod array-based UV photoconductive sensors.

In comparison with our previous study, the Al-doped $\mathrm{ZnO}$ nanorod arrays show better UV sensing than that of the $\mathrm{ZnO}$ nanoparticle thin film especially in term of photocurrent and responsivity. The $\mathrm{ZnO}$ nanoparticles used in UV photoconductive sensors tend to exhibit sluggish photoresponses; this is likely the result of grain boundary effects and the presence of surface defects, which reduce the carrier mobility and increase carrier scattering within the thin film $[49,55,57,58]$. The use of the nanorod arrays enhanced the UV photoconductive sensor performance due to their high mobility and high surface-to-volume ratio. Bera et al. emphasised that the UV photoconductivity of $\mathrm{ZnO}$ is strongly related to the surface reaction processes; thus, the high surface-to-volume ratios in the one-dimensional (1D) nanostructure (i.e., nanorod) enhance the sensitivity of the sensor beyond that of the $\mathrm{ZnO}$ nanoparticle thin film [13]. According to Soci et al., 1D structures have several advantages over bulk or thin films in UV sensor applications, including light scattering enhancements that reduce optical losses, improved light absorption, high photosensitivity due to the high gain, and the possibility to integrate functionalities within single 1D devices [59]. The prolonged photocarrier lifetime, which is due to charge separation promoted by surface states, and the reduction in carrier transit time, which can be achieved in high-quality, lowdefect $\mathrm{ZnO}$ nanorods together with small gaps in the metal contacts, both contribute to the high gain in nanorod-based devices $[59,60]$. 


\section{Conclusions}

UV photoconductive sensors were successfully fabricated using $\mathrm{Al}$-doped $\mathrm{ZnO}$ nanorod arrays that were annealed at $500^{\circ} \mathrm{C}$ in different environments. The nanorod arrays were prepared on seed-layer-coated glass substrates using sonicated sol-gel immersion. FESEM images reveal that the deposited nanorods have an average diameter of $60 \mathrm{~nm}$ with a thickness of approximately $600 \mathrm{~nm}$ including the seed layer. Interestingly, after annealing in different environments (i.e., oxygen, air, and vacuum), the morphology and thickness of the nanorod arrays remain almost unchanged. The XRD patterns indicate that the as-grown and annealed nanorod arrays have a prominent peak for the (002) orientation, with the oxygen-annealed nanorod arrays presenting the highest peak intensity, followed by the air-annealed, vacuumannealed and as-grown nanorod arrays. For the vacuumannealed nanorod arrays, the XRD measurement detected the appearance of $\mathrm{Zn}$ peaks, which indicates that the nanorod arrays are rich in $\mathrm{Zn}$ interstitial defects. The prepared nanorod arrays also show high transmittance properties in the visible region with an average transmittance of over $72 \%$. According to the PL measurement spectra, the vacuumannealed nanorod arrays have the highest UV emission peak intensity compared to the other samples. However, the airannealed nanorod arrays show slightly lower UV emission peak intensity than those of the vacuum-annealed nanorod arrays, whereas for the oxygen-annealed nanorod arrays, the UV emission peak intensity is lower than that of the air-annealed arrays but higher than that of the as-grown nanorod arrays. Notably, we also observed that the oxygenannealed nanorod arrays have visible emission that is centred at $630 \mathrm{~nm}$, at which the intensity was almost similar with the UV emission. This visible emission was correlated with oxygen interstitials or adsorbed oxygen on the nanorod surface. The $I-V$ measurement spectra show that oxygen-annealed nanorod arrays have higher resistance values than the other samples, which was due to oxygen adsorption on the nanorod surface. In contrast, the vacuum-annealed nanorod arrays have low resistance values, which is due to the high concentration of $\mathrm{Zn}$ interstitials. The photocurrent measurement spectra indicate that the vacuum-annealed nanorod arrays exhibit the highest photocurrent, followed by the airannealed, oxygen-annealed, and as-grown nanorod arrays. However, the oxygen-annealed nanorod-array-based UV photoconductive sensor shows the highest sensitivity value of 55.6. This result was due to the significant reduction of the dark current and suitable surface conditions of the nanorod arrays, which facilitates fast oxygen adsorption and desorption processes. In addition, the oxygen-annealed nanorod arrays also show lower rise and decay time constants compared to the other samples.

\section{Acknowledgments}

One of the authors (M. H. Mamat) would like to thank the Universiti Teknologi MARA (UiTM), Malaysia, and the Jabatan Perkhidmatan Awam (JPA), Malaysia, for funding in the form of a scholarship. The authors also would like to thank the Research Management Institute (RMI) of UiTM and the Ministry of Higher Education of Malaysia for their financial support of this research. The authors thank the Faculty of Applied Sciences at UiTM for the use of their XRD facility. The authors thank Mr. Mohd Zamri Yusop and Professor Dr. Masaki Tanemura from the Nagoya Institute of Technology (NIT), Japan, for their assistance in the TEM and SAED measurements.

\section{References}

[1] J. Y. Chen and K. W. Sun, "Growth of vertically aligned $\mathrm{ZnO}$ nanorod arrays as antireflection layer on silicon solar cells," Solar Energy Materials and Solar Cells, vol. 94, no. 5, pp. 930934, 2010.

[2] F. Xu, M. Dai, Y. Lu, and L. Sun, "Hierarchical ZnO nanowirenanosheet architectures for high power conversion efficiency in dye-sensitized solar cells," Journal of Physical Chemistry C, vol. 114, no. 6, pp. 2776-2782, 2010.

[3] Z. X. Zhou, J. X. Gao, and Z. L. Wu, "Materials and Devices research of PPV-ZnO Nanowires for heterojunction solar cells," Journal of Nanomaterials, vol. 2012, Article ID 368236, 4 pages, 2012.

[4] S. P. Chang and T. H. Chang, "Use of the thermal chemical vapor deposition to fabricate light-emitting diodes based on zno nanowire/p-GaN heterojunction,", Journal of Nanomaterials, vol. 2011, Article ID 903176, 4 pages, 2011.

[5] J. Singh, S. S. Patil, M. A. More, D. S. Joag, R. S. Tiwari, and O. N. Srivastava, "Formation of aligned $\mathrm{ZnO}$ nanorods on selfgrown $\mathrm{ZnO}$ template and its enhanced field emission characteristics," Applied Surface Science, vol. 256, no. 21, pp. 61576163, 2010.

[6] M. H. Mamat, Z. Khusaimi, M. F. Malik, M. M. Zahidi, and M. R. Mahmood, "Ultra-violet sensing characteristic and field emission properties of vertically aligned aluminum doped zinc oxide nanorod arrays," in Proceedings of the International Conference on Enabling Science and Nanotechnology (ESciNano'10), Kuala Lumpur, Malaysia, December 2010.

[7] S. Moradi, P. A. Azar, S. R. Farshid, S. A. Khorrami, and M. H. Givianrad, "Effect of Additives on Characterization and Photocatalytic Activity of $\mathrm{Tio}_{2} / \mathrm{ZnO}$ Nanocomposite Prepared via Sol-Gel Process," International Journal of Chemical Engineering, vol. 2012, Article ID 215373, 5 pages, 2012.

[8] M. H. Mamat, Z. Khusaimi, M. Z. Musa, M. F. Malek, and M. Rusop, "Fabrication of ultraviolet photoconductive sensor using a novel aluminium-doped zinc oxide nanorodnanoflake network thin film prepared via ultrasonic-assisted sol-gel and immersion methods," Sensors and Actuators, A, vol. 171, pp. 241-247, 2011.

[9] O. Lupan, G. Chai, L. Chow et al., "Ultraviolet photoconductive sensor based on single $\mathrm{ZnO}$ nanowire," Physica Status Solidi (A), vol. 207, no. 7, pp. 1735-1740, 2010.

[10] H. Jeong, K. S. Kim, Y. H. Kim et al., "A crossbar-type high sensitivity ultraviolet photodetector array based on a one hole-one nanorod configuration via nanoimprint lithography," Nanotechnology, vol. 22, no. 27, Article ID 275310, 2011.

[11] B. Yuan, X. J. Zheng, Y. Q. Chen, B. Yang, and T. Zhang, "High photosensitivity and low dark current of photoconductive semiconductor switch based on $\mathrm{ZnO}$ single nanobelt," SolidState Electronics, vol. 55, no. 1, pp. 49-53, 2011. 
[12] J. P. Kar, S. N. Das, J. H. Choi, Y. A. Lee, T. Y. Lee, and J. M. Myoung, "Fabrication of UV detectors based on $\mathrm{ZnO}$ nanowires using silicon microchannel," Journal of Crystal Growth, vol. 311, no. 12, pp. 3305-3309, 2009.

[13] A. Bera, T. Ghosh, and D. Basak, "Enhanced photoluminescence and photoconductivity of $\mathrm{ZnO}$ nanowires with sputtered Zn," ACS Applied Materials and Interfaces, vol. 2, no. 10, pp. 2898-2903, 2010.

[14] G. Y. Chai, L. Chow, O. Lupan et al., "Fabrication and characterization of an individual $\mathrm{ZnO}$ microwire-based UV photodetector," Solid State Sciences, vol. 13, no. 5, pp. 1205-1210, 2011.

[15] M. Rosina, P. Ferret, P. H. Jouneau et al., "Morphology and growth mechanism of aligned $\mathrm{ZnO}$ nanorods grown by catalyst-free MOCVD," Microelectronics Journal, vol. 40, no. 2, pp. 242-245, 2009.

[16] G. M. Fuge, T. M. S. Holmes, and M. N. R. Ashfold, "Ultrathin aligned $\mathrm{ZnO}$ nanorod arrays grown by a novel diffusive pulsed laser deposition method," Chemical Physics Letters, vol. 479, no. 1-3, pp. 125-127, 2009.

[17] M. H. Mamat, Z. Khusaimi, M. M. Zahidi et al., "Controllable growth of vertically aligned aluminum-doped zinc oxide nanorod arrays by sonicated sol-gel immersion method depending on precursor solution volumes," Japanese Journal of Applied Physics, vol. 50, no. 6, Article ID 06GH04, 2011.

[18] M. Mehrabian, R. Azimirad, K. Mirabbaszadeh, H. Afarideh, and M. Davoudian, "UV detecting properties of hydrothermal synthesized ZnO nanorods," Physica E, vol. 43, no. 6, pp. 1141$1145,2011$.

[19] M. H. Mamat, Z. Khusaimi, M. Z. Musa, M. Z. Sahdan, and M. Rusop, "Novel synthesis of aligned Zinc oxide nanorods on a glass substrate by sonicated sol-gel immersion," Materials Letters, vol. 64, no. 10, pp. 1211-1214, 2010.

[20] M. H. Mamat, M. Z. Sahdan, S. Amizam, H. A. Rafaie, Z. Khusaimi, and M. Rusop, "Properties of nanostructured zinc oxide by hydro-thermal aqueous chemical growth method," in Proceedings of the International Conference on Nanoscience and Nanotechnology (Nano-SciTech'08), pp. 586-590, Selangor, Malaysia, November 2008.

[21] A. Bera and D. Basak, "Pd-nanoparticle-decorated $\mathrm{ZnO}$ nanowires: ultraviolet photosensitivity and photoluminescence properties," Nanotechnology, vol. 22, no. 26, Article ID 265501, 2011.

[22] A. Bera and D. Basak, "Effect of surface capping with poly(vinyl alcohol) on the photocarrier relaxation of $\mathrm{ZnO}$ nanowires.," ACS applied materials \& interfaces, vol. 1, no. 9, pp. 2066-2070, 2009.

[23] L. Qin, C. Shing, S. Sawyer, and P. S. Dutta, "Enhanced ultraviolet sensitivity of zinc oxide nanoparticle photoconductors by surface passivation," Optical Materials, vol. 33, no. 3, pp. 359-362, 2011.

[24] N. Chantarat, Y. W. Chen, S. Y. Chen, and C. C. Lin, "Enhanced UV photoresponse in nitrogen plasma $\mathrm{ZnO}$ nanotubes," Nanotechnology, vol. 20, no. 39, Article ID 395201, 2009.

[25] B. Angadi, H. C. Park, H. W. Choi, J. W. Choi, and W. K. Choi, "Oxygen plasma treated epitaxial $\mathrm{ZnO}$ thin films for Schottky ultraviolet detection," Journal of Physics D, vol. 40, no. 5, article no. 016, pp. 1422-1425, 2007.

[26] H. W. Ra, R. Khan, J. T. Kim, B. R. Kang, K. H. Bai, and Y. $\mathrm{H}$. Im, "Effects of surface modification of the individual $\mathrm{ZnO}$ nanowire with oxygen plasma treatment," Materials Letters, vol. 63, no. 28, pp. 2516-2519, 2009.
[27] W. Park, G. Jo, W. K. Hong et al., "Enhancement in the photodetection of $\mathrm{ZnO}$ nanowires by introducing surfaceroughness-induced traps," Nanotechnology, vol. 22, no. 20, Article ID 205204, 2011.

[28] S. P. Chang, R. W. Chuang, S. J. Chang, C. Y. Lu, Y. Z. Chiou, and S. F. Hsieh, "Surface $\mathrm{HCl}$ treatment in $\mathrm{ZnO}$ photoconductive sensors," Thin Solid Films, vol. 517, no. 17, pp. 5050-5053, 2009.

[29] D. Byrne, E. McGlynn, M. O. Henry, K. Kumar, and G. Hughes, "A novel, substrate independent three-step process for the growth of uniform $\mathrm{ZnO}$ nanorod arrays," Thin Solid Films, vol. 518, no. 16, pp. 4489-4492, 2010.

[30] T. G. G. Maffeis, M. W. Penny, A. Castaing, O. J. Guy, and S. P. Wilks, "XPS investigation of vacuum annealed vertically aligned ultralong ZnO nanowires," Surface Science, vol. 606, pp. 99-103, 2012.

[31] M. Z. Sahdan, M. H. Mamat, M. Salina, Z. Khusaimi, U. M. Noor, and M. Rusop, "Heat treatment effects on the surface morphology and optical properties of $\mathrm{ZnO}$ nanostructures," Physica Status Solidi C, vol. 7, no. 9, pp. 2286-2289, 2010.

[32] S. Dhara and P. Giri, "Enhanced UV photosensitivity from rapid thermal annealed vertically aligned $\mathrm{ZnO}$ nanowires," Nanoscale Research Letters, vol. 6, p. 504, 2011.

[33] K.-P. Kim, D. Chang, S. K. Lim, S. K. Lee, H. K. Lyu, and D. K. Hwang, "Thermal annealing effects on the dynamic photoresponse properties of Al-doped $\mathrm{ZnO}$ nanowires network," Current Applied Physics, vol. 11, pp. 1311-1314, 2011.

[34] M. H. Mamat, Z. Khusaimi, M. Z. Musa, M. F. Malek, and M. Rusop, "Ultraviolet sensing mechanism and characteristics of environmentally friendly aligned aluminium doped zinc oxide nanorod arrays prepared using low cost solution growth method," Materials Research Innovations, vol. 15, p. s148, 2011.

[35] H. Zhou, G.-J. Fang, N. Liu, and X. Z. Zhao, "Effects of thermal annealing on the performance of $\mathrm{Al} / \mathrm{ZnO}$ nanorods/ $\mathrm{Pt}$ structure ultraviolet photodetector," Materials Science and Engineering B, vol. 176, no. 9, pp. 740-744, 2011.

[36] M. H. Mamat, M. Z. Sahdan, Z. Khusaimi, A. Z. Ahmed, S. Abdullah, and M. Rusop, "Influence of doping concentrations on the aluminum doped zinc oxide thin films properties for ultraviolet photoconductive sensor applications," Optical Materials, vol. 32, no. 6, pp. 696-699, 2010.

[37] M. Qiu, Z. Ye, J. Lu et al., "Growth and properties of $\mathrm{ZnO}$ nanorod and nanonails by thermal evaporation," Applied Surface Science, vol. 255, no. 7, pp. 3972-3976, 2009.

[38] W. M. Kwok, A. B. Djurišić, Y. H. Leung et al., "Influence of annealing on stimulated emission in $\mathrm{ZnO}$ nanorods," Applied Physics Letters, vol. 89, no. 18, Article ID 183112, 2006.

[39] J. W. P. Hsu, D. R. Tallant, R. L. Simpson, N. A. Missert, and R. G. Copeland, "Luminescent properties of solution-grown $\mathrm{ZnO}$ nanorods," Applied Physics Letters, vol. 88, no. 25, Article ID 252103, 2006.

[40] J. Zhang and W. Que, "Preparation and characterization of solgel $\mathrm{Al}$-doped $\mathrm{ZnO}$ thin films and $\mathrm{ZnO}$ nanowire arrays grown on Al-doped $\mathrm{ZnO}$ seed layer by hydrothermal method," Solar Energy Materials and Solar Cells, vol. 94, no. 12, pp. 2181-2186, 2010.

[41] M. K. Patra, K. Manzoor, M. Manoth, S. R. Vadera, and N. Kumar, "Studies of luminescence properties of $\mathrm{ZnO}$ and $\mathrm{ZnO}$ : Zn nanorods prepared by solution growth technique," Journal of Luminescence, vol. 128, no. 2, pp. 267-272, 2008.

[42] R. Xie, T. Sekiguchi, T. Ishigaki et al., "Enhancement and patterning of ultraviolet emission in $\mathrm{ZnO}$ with an electron beam," Applied Physics Letters, vol. 88, no. 13, Article ID 134103, 2006. 
[43] Z.-M. Liao, H. Z. Zhang, Y. B. Zhou, J. Xu, J. M. Zhang, and D. P. Yu, "Surface effects on photoluminescence of single $\mathrm{ZnO}$ nanowires," Physics Letters, Section A, vol. 372, no. 24, pp. 4505-4509, 2008.

[44] J. Lee, J. Chung, and S. Lim, "Improvement of optical properties of post-annealed $\mathrm{ZnO}$ nanorods," Physica E, vol. 42, no. 8, pp. 2143-2146, 2010.

[45] Y. H. Leung, A. B. Djurišić, Z. T. Liu, D. Li, M. H. Xie, and W. K. Chan, "Defect photoluminescence of $\mathrm{ZnO}$ nanorods synthesized by chemical methods," Journal of Physics and Chemistry of Solids, vol. 69, no. 2-3, pp. 353-357, 2008.

[46] D. Wang and N. Reynolds, "Photoluminescence of Zinc Oxide nanowires: the effect of surface band bending," ISRN Condensed Matter Physics, vol. 2012, Article ID 950354, 6 pages, 2012.

[47] T. Ghosh and D. Basak, "Highly enhanced ultraviolet photoresponse property in $\mathrm{Cu}$-doped and $\mathrm{Cu}-\mathrm{Li}$ co-doped $\mathrm{ZnO}$ films," Journal of Physics D, vol. 42, no. 14, Article ID 145304, 2009.

[48] M. Li, G. Xing, L. F. N. Ah Qune et al., "Tailoring the charge carrier dynamics in $\mathrm{ZnO}$ nanowires: the role of surface hole/ electron traps," Physical Chemistry Chemical Physics, vol. 14, pp. 3075-3082, 2012.

[49] J. H. Jun, H. Seong, K. Cho, B. M. Moon, and S. Kim, "Ultraviolet photodetectors based on $\mathrm{ZnO}$ nanoparticles," Ceramics International, vol. 35, no. 7, pp. 2797-2801, 2009.

[50] S. Mridha, M. Nandi, A. Bhaumik, and D. Basak, "A novel and simple approach to enhance ultraviolet photosensitivity: activated-carbon-assisted growth of $\mathrm{ZnO}$ nanoparticles," Nanotechnology, vol. 19, no. 27, Article ID 275705, 2008.

[51] A. Bera and D. Basak, "Role of defects in the anomalous photoconductivity in $\mathrm{ZnO}$ nanowires," Applied Physics Letters, vol. 94, no. 16, Article ID 163119, 2009.

[52] C. H. Ahn, W. S. Han, B. H. Kong, and H. K. Cho, "Ga-doped $\mathrm{ZnO}$ nanorod arrays grown by thermal evaporation and their electrical behavior," Nanotechnology, vol. 20, no. 1, Article ID 015601, 2009.

[53] A. F. Lotus, Y. C. Kang, J. I. Walker, R. D. Ramsier, and G. G. Chase, "Effect of aluminum oxide doping on the structural, electrical, and optical properties of zinc oxide (AOZO) nanofibers synthesized by electrospinning," Materials Science and Engineering B, vol. 166, no. 1, pp. 61-66, 2010.

[54] C.-H. Hsu and D.-H. Chen, "Synthesis and conductivity enhancement of Al-doped $\mathrm{ZnO}$ nanorod array thin films," Nanotechnology, vol. 21, no. 28, Article ID 285603, 2010.

[55] S. Mridha and D. Basak, "Aluminium doped ZnO films: electrical, optical and photoresponse studies," Journal of Physics D, vol. 40, no. 22, pp. 6902-6907, 2007.

[56] B. K. Sharma and N. Khare, "Stress-dependent band gap shift and quenching of defects in Al-doped $\mathrm{ZnO}$ films," Journal of Physics D, vol. 43, no. 46, Article ID 465402, 2010.

[57] X. G. Zheng, Q. S. Li, J. P. Zhao et al., "Photoconductive ultraviolet detectors based on $\mathrm{ZnO}$ films," Applied Surface Science, vol. 253, no. 4, pp. 2264-2267, 2006.

[58] J. M. Liu, Y. B. Xia, L. J. Wang, Q. F. Su, and W. M. Shi, "Effect of grain size on the electrical properties of ultraviolet photodetector with $\mathrm{ZnO}$ /diamond film structure," Journal of Crystal Growth, vol. 300, no. 2, pp. 353-357, 2007.

[59] C. Soci, A. Zhang, X. Y. Bao, H. Kim, Y. Lo, and D. Wang, "Nanowire photodetectors," Journal of Nanoscience and Nanotechnology, vol. 10, no. 3, pp. 1430-1449, 2010.

[60] C. Sheng-Po, L. Chien-Yuan, C. Shoou-Jinn, C. Yu-Zung, H. Ting-Jen, and H. Cheng-Liang, "Electrical and optical characteristics of UV photodetector with interlaced ZnO nanowires,"
IEEE Journal of Selected Topics in Quantum Electronics, vol. 17, pp. 990-995, 2011. 

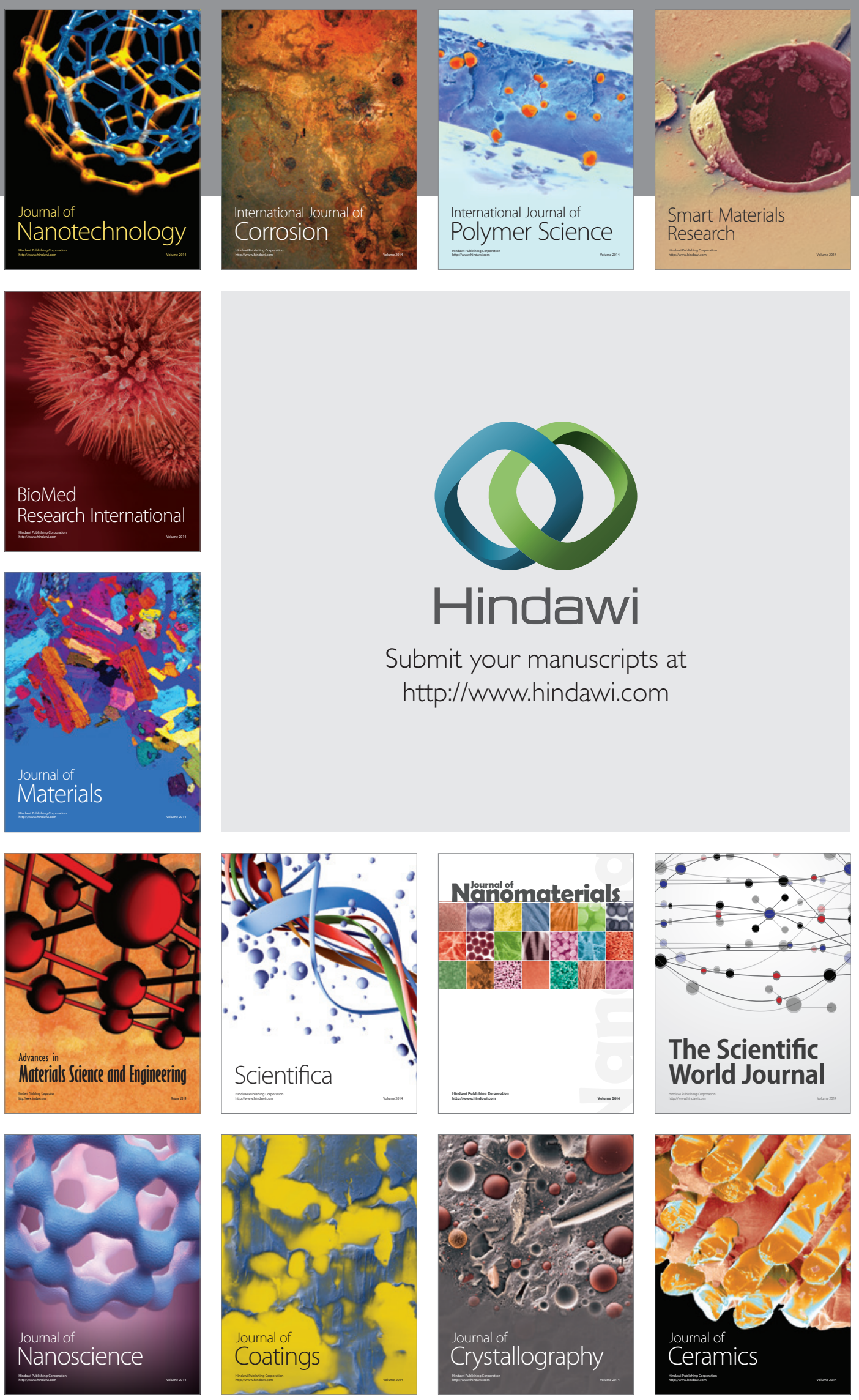

The Scientific World Journal

Submit your manuscripts at

http://www.hindawi.com

\section{World Journal}

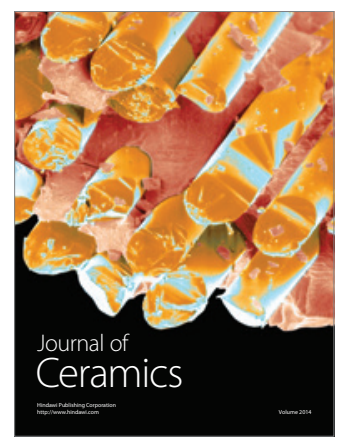

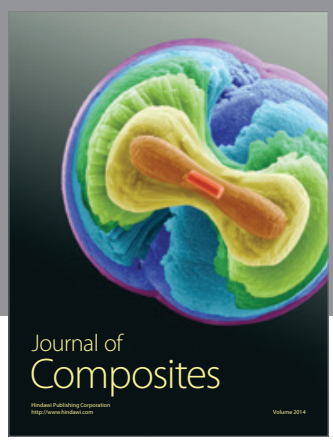
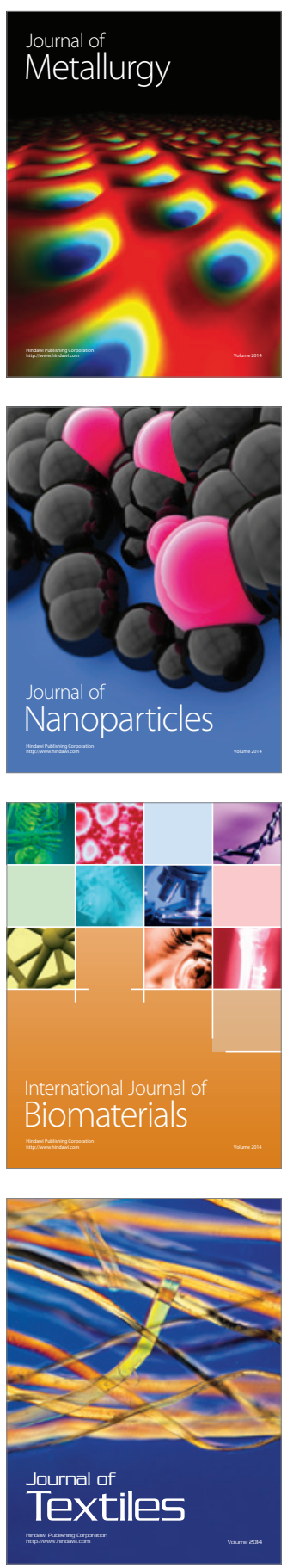